This item was submitted to Loughborough's Research Repository by the author.

Items in Figshare are protected by copyright, with all rights reserved, unless otherwise indicated.

\title{
Transient elastohydrodynamic lubrication of rough new or worn piston compression ring conjunction with an out-of-round cylinder bore
}

PLEASE CITE THE PUBLISHED VERSION

http://dx.doi.org/10.1177/1350650111431028

PUBLISHER

(c) Sage

VERSION

AM (Accepted Manuscript)

LICENCE

CC BY-NC-ND 4.0

\section{REPOSITORY RECORD}

Rahmani, Ramin, Stephanos Theodossiades, Homer Rahnejat, and Brian Fitzsimons. 2019. "Transient Elastohydrodynamic Lubrication of Rough New or Worn Piston Compression Ring Conjunction with an Out-ofround Cylinder Bore". figshare. https://hdl.handle.net/2134/12902. 
This item was submitted to Loughborough's Institutional Repository (https://dspace.lboro.ac.uk/) by the author and is made available under the following Creative Commons Licence conditions.

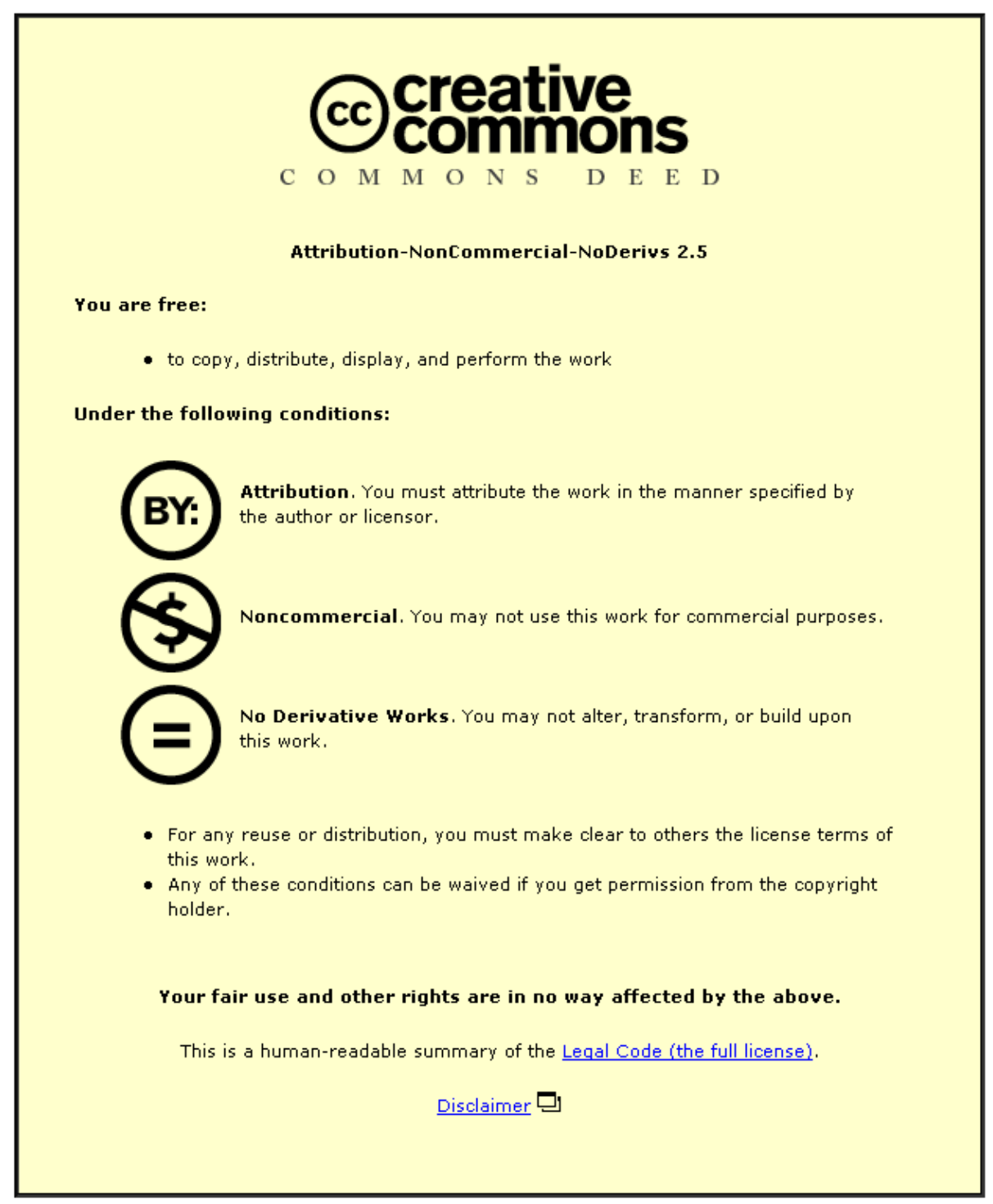

For the full text of this licence, please go to: http://creativecommons.org/licenses/by-nc-nd/2.5/ 
Proceedings of the Institution of Mechanical Engineers, Part J: Journal of Engineering Tribology, 2012, Vol. 226, No. 4, pp. 284-305

(Accepted Version)

Transient elastohydrodynamic lubrication of rough new or worn piston compression ring conjunction with an out-of-round cylinder bore

\author{
R. Rahmani ${ }^{1}$, S. Theodossiades ${ }^{1}$, H. Rahnejat ${ }^{1 *}$ and B. Fitzsimons ${ }^{2 \S}$ \\ ${ }^{1}$ Wolfson School of Mechanical \& Manufacturing Engineering, Loughborough University, \\ Loughborough, UK \\ ${ }^{2}$ Aston Martin Lagonda, Gaydon, Warwickshire, UK \\ ${ }^{\S}$ Visiting Professor at Wolfson School, Loughborough University \\ *Corresponding author: h.rahnejat@lboro.ac.uk
}

\begin{abstract}
Real cylinder bores are out-of-round and axially asymmetrical. The top compression ring, nominally an incomplete circle, is subjected to ring tension and cyclic combustion force in order to conform to the bore surface. The bounding surfaces are rough and their conjunction is subject to a transient tribological state. Therefore, the ring-bore conjunction is only partially conforming for most of the engine cycle. The conjunction may be viewed as a problem of scale, depending on the analysis carried out at a certain bore order (out-ofroundness). Therefore, the contact may be viewed as a multi-lobed rough conjunction, where the regime of lubrication may vary from hydrodynamics to mixed with dominant asperity friction at piston reversals. Measured bores and ring profiles are used to predict conjunctional power loss and percentage fuel energy consumed. Furthermore, lubricant flow through the ring is predicted throughout the engine cycle. These measures are key industrial design
\end{abstract}


Proceedings of the Institution of Mechanical Engineers, Part J: Journal of Engineering Tribology, 2012, Vol. 226, No. 4, pp. 284-305

(Accepted Version)

drivers for fuel efficiency and reduction of emissions. The results show that the effect of bore out-of-roundness can be even more significant than the surface topography.

Keywords: Piston compression ring, Ring/bore conformability, Surface roughness, Ring wear, frictional losses

\section{Nomenclature}

A

Apparent contact area

$A_{a}$

Asperity contact area

$A_{n}, B_{n}$

Fourier coefficients

$b$

Ring axial face-width

$d$

Ring thickness

$D^{*}$

Influence coefficient matrix

E

Young's modulus of elasticity of the ring

$E_{l} \quad$ Young's modulus of elasticity of the liner

$E^{\prime} \quad$ Equivalent (reduced) modulus of elasticity

$f_{b} \quad$ Boundary friction

$f_{t}$

Total friction

$f_{v} \quad$ Viscous friction

$F_{T} \quad$ Ring tension force

$F_{G} \quad$ Combustion gas force 
Proceedings of the Institution of Mechanical Engineers, Part J: Journal of Engineering Tribology, 2012, Vol. 226, No. 4, pp. 284-305
$F_{2}, F_{5 / 2}$
Statistical functions
$g$
Ring end gap
G
ring-bore gap
$h$
Elastic film shape
$h_{m}$
Minimum film thickness
$h_{s}$
Ring axial profile
Ring cross-sectional second area moment of inertia
$K, K^{\prime}$
Conformability coefficient (factor)
l
Connecting rod length
$L$
Ring peripheral length
$m$
Mass of the ring
$n$
Bore order
$N$
Maximum bore order
$p_{a t m}$
Atmospheric pressure
$p_{c}$
Cavitation/lubricant vaporization pressure
$p_{h}$
Hydrodynamic pressure
$p_{g b}$
Gas pressure acting behind the ring
$p_{L}$
Pressure on the lower face of the ring (inter-ring pressure)
$p_{U}$
Pressure on the upper face of the ring

(Accepted Version) 
Proceedings of the Institution of Mechanical Engineers, Part J: Journal of Engineering Tribology, 2012, Vol. 226, No. 4, pp. 284-305

$P_{f}$

(Accepted Version)

$P_{f b} \quad$ Frictional power loss due to boundary interactions

$P_{f v} \quad$ Frictional power loss due to lubricant viscous shear

$q$

Lubricant volumetric flow rate

$r$

Crank-pin radius

$r_{0}$

Nominal bore radius

$S$

Integration variable

$t$

Time

$U_{1}, U_{2} \quad$ Surface velocities of contacting bodies

$u$

Amplitude of liner waviness that the ring can conform

$\vec{V}$

Velocity vector

W

Contact load

$W_{a} \quad$ Load share of asperities

$W_{h} \quad$ Load carried by the lubricant film

$x, y \quad$ Cartesian coordinates (along axial and circumferential directions)

$x_{C} \quad$ Oil film rupture point

Z Pressure-viscosity index

\section{Greek symbols}


Proceedings of the Institution of Mechanical Engineers, Part J: Journal of Engineering Tribology, 2012, Vol. 226, No. 4, pp. 284-305

(Accepted Version)

$\alpha^{*} \quad$ Modified pressure-viscosity coefficient

$\alpha_{0} \quad$ Pressure-viscosity coefficient

$\beta \quad$ Damping factor

$\gamma \quad$ Over/under-relaxation factor

$\delta \quad$ Local deformation (contact deflection)

$\Delta r \quad$ Deviation of ring radius from an idealised circle

$\Delta U \quad$ Sliding velocity

$\Delta x, \Delta y \quad$ Discrete steps in the $x$ and $y$ directions

$\Delta$

Ring global deformation due to fitment and gas pressure

Number of asperities per unit contact area

$\eta$

Lubricant dynamic viscosity

$\eta_{0}$

Lubricant dynamic viscosity at atmospheric pressure

$\theta$

Bore circumferential angle

$\kappa$

Average asperity tip radius

$\lambda$

Stribeck’s oil film parameter

$v$

Poisson's ratio of the ring material

$v_{l}$

Poisson's ratio of the liner material

$\xi \quad$ Distorted bore profile 
Proceedings of the Institution of Mechanical Engineers, Part J: Journal of Engineering Tribology, 2012, Vol. 226, No. 4, pp. 284-305

(Accepted Version)

$\rho \quad$ Lubricant density

$\rho_{0} \quad$ Lubricant density at atmospheric pressure

$\sigma_{l} \quad$ Liner surface roughness $\mathrm{Ra}$

$\sigma_{r} \quad$ Ring surface roughness Ra

$\varsigma \quad$ Pressure coefficient for boundary shear strength of asperities

$\tau \quad$ Shear stress

$\tau_{0}$

Eyring shear stress

$\varphi$

Crank angle

$\chi$

Adjusting parameter

$\omega$

Angular velocity of the engine

\section{Introduction}

Stringent legislations for vehicle emissions and the ever-rising cost of fuel have resulted in a drive for fuel efficiency. Another trend, in contrast to the mounting volume of regulations, is the customer-driven desire for increased output power. Thus, in the pervading global competition minimisation of engine losses has become a critical objective as it would contribute to all the competing and often contradictory demands. Aside from the main source of inefficiency; thermal losses, the other stumbling block in achieving the aforementioned contradictory demands is the need to reduce mechanical losses, dominated by friction. Mechanical losses account for $20 \%$ of the input fuel energy in an internal combustion engine, at least $45 \%$ of which is due to friction of the piston system [1-2]. In fact, friction caused by piston rings can account for up to $20 \%$ of friction mean effective pressure (FMEP) [3]. 
Proceedings of the Institution of Mechanical Engineers, Part J: Journal of Engineering Tribology, 2012, Vol. 226, No. 4, pp. 284-305

(Accepted Version)

The top compression ring's main function is to seal the combustion chamber and guard against any loss of power. Although evidence points to the understanding of this critical function of the ring right from the outset of its use, the extent of its conformity to the cylinder bore surface has been a question of debate. Good conformability is required for its primary functional assurance. However, this would lead to excessive friction, generation of heat and ensuing wear. Another function of the ring is to carry some of the heat away from its conjunction with the bore surface. This is particularly important as any film of lubricant formed is diminutive in thickness and hence insufficient to aid convection cooling.

Real cylinder bores are out-of-round, not only in any given cross-section, but also with variations along the length of the cylinder. Although an incomplete circular ring allows global thermo-elastic deformation ideally to conform to the bore surface, it is now well established that only a partially conforming conjunction results. This means that the sealing requirement for the ring is only partially met. Thus, a film of lubricant can be entrained into the conjunction and becomes pressurised to carry the contact load. Since, the instantaneous contact load varies according to the ring tension and pressure differential acting behind it at any instant of time, the lubricant film thickness would alter in a transient manner. Hence, the regime of lubrication is subject to this transience and is also affected by the ring geometry and contact kinematics (sliding speed and local approach and separation of surfaces, termed as the squeeze film effect).

The regime of lubrication determines an assortment of mechanisms which underlie friction; viscous shear of a thin film of oil, pressure gradient and asperity interactions. Therefore, the transient nature of ring-bore contact and the interaction of many parameters make the tribology of this conjunction among the most complex according to Priest and Taylor [4]. 
Proceedings of the Institution of Mechanical Engineers, Part J: Journal of Engineering Tribology, 2012, Vol. 226, No. 4, pp. 284-305

(Accepted Version)

As the result of the multi-variate nature of the problem, alluded to above, analysis of ringbore conjunction has been deemed as essential and has evolved with models of an everincreasing degree of complexity. An initial analysis by Furuhama [5] may be considered as one of the fore-running contributions. Hitherto, there has been a considerable volume of literature in the field, mostly focusing on one or a few parameters of interest. They include investigations by Dowson et al [6] and Hwu and Weng [7], both presenting one dimensional elastohydrodynamics of ring-bore conjunction along the ring's face-width. Aside from the one dimensional nature of the analysis, these earlier works assumed nominally smooth surfaces, fully flooded conjunctions and isothermal conditions. Later Jeng [8-9] extended this approach to include the effect of starvation, which is prevalent in compression ring-bore interactions. Furthermore, a semi-analytic solution was proposed. Analytical solutions, as opposed to numerical methods, are rather elegant and computationally efficient. However, they are only possible when some simplifying assumptions are made and justified.

One assumption often made is to disregard the rough nature of the contiguous surfaces. However, experience points to the contrary as evident from wear of surfaces, particularly in locations with unfavourable kinematic conditions, such as the top and bottom dead centres. Patir and Cheng [10] introduced a new form of Reynolds equation, based on average flow factors for lubricant motion through real rough surfaces. This approach enabled the inclusion of surface roughness in terms of topographical parameters such as the composite surface Ra into the numerical analysis. This approach was adopted by Sui and Ariga [11] for an analysis of ring pack lubrication. They showed that gradual ring wear yields better conforming geometry which can improve performance. Akalin and Newaz [12-13] used a similar approach to predict generated friction throughout the 4-stroke engine cycle. They showed that the analysis should be based on the mixed regime of lubrication to yield realistic predictions. In particular, they compared their predictions with experimental results of a motored engine 
Proceedings of the Institution of Mechanical Engineers, Part J: Journal of Engineering Tribology, 2012, Vol. 226, No. 4, pp. 284-305

(Accepted Version)

test rig at Chevrolet carried out by Furuhama and Sasaki [14]. The predictions conformed reasonably well to the experimental measurements of friction. Akalin and Newaz's [12-13] study confirmed the prevalent mixed regime of lubrication at and in the immediate vicinity of piston reversal points.

The problem with one dimensional contact analysis along the ring face-width is that it implies good conformance of the ring to the cylinder liner around its periphery. This makes the analysis representative for line contact. It justifies the omission of pressure gradient in the circumferential direction, when compared with the sharp rise rate of the same along the ring face-width. However, in reality the bore is not an ideal right circular cylinder. Therefore, insitu shape of the ring within the cylinder results in variation of the ring/bore gap (clearance) circumferentially. Hence, a two-dimensional solution to Reynolds equation is necessary. Ma et al [15] reported such an analysis, post conformability analysis of an incomplete circular compression ring within the cylinder, subjected to the outward elastic tensile force of the ring and augmented by the combustion pressure acting behind it. These outward radial forces strive to adhere the ring to the bore surface and are countered by the contact pressure distribution. The in-situ shape of the ring and thus the resulting clearance profile at any instant of time (at any crank angle) is obtained through conformability analysis, which was originally proposed by Hill and Newman [3]. Using this approach and accounting for combustion variation throughout an engine 4-stroke cycle, Mishra et al [16-17] undertook two-dimensional analysis of compression ring-cylinder liner conjunction, taking into account combined elastohydrodynamic and asperity interactions; the latter based on the approach initially expounded by Hu et al [18] and Bolander et al [19]. The surface topographies of a cross-hatched plateau honed advanced cylinder liner and the mating compression ring were represented by their $\mathrm{R}_{\mathrm{k}}$ roughness values. The analysis of Mishra et al [17] showed that for most of the power stroke at least part of the contact remained in the mixed regime of 
Proceedings of the Institution of Mechanical Engineers, Part J: Journal of Engineering Tribology, 2012, Vol. 226, No. 4, pp. 284-305

(Accepted Version)

lubrication, the extent of which increased near the dead centres with a decreasing piston sliding speed. The significance of these findings was that the regime of lubrication is not only temporally transient (i.e. at instants of ring reversal), but also spatially so at any instant of time. Comparison of their predictions with the experimental work of Furuhama and Sasaki [14] showed even better agreement than the one-dimensional mixed elastohydrodynamics of Akalin and Newaz [13].

There are a variety of causes which may account for the differences still remaining between the predictions and measurements. One is the isothermal nature of all the analyses referred to thus far. Both boundary and viscous friction generate heat, which in turn affect the lubricant viscosity and consequently reduce the film thickness even further. This may account for the differences in monitored and predicted friction, where hydrodynamic regime of lubrication is dominant, such as in the intake stroke and most of the compression and exhaust strokes. However, the main contribution to friction occurs in the power stroke. Here as Mishra et al [17] have shown, a mixed regime of lubrication is nearly always present to some extent. Aside from thermal shear thinning of the lubricant, a sufficient supply of the lubricant contrary to the common assumption may not always exist. The inter-ring pressure (between the compression ring and the oil control ring) is also not the commonly assumed atmospheric crank pressure in the power stroke. This issue is addressed in the works of D'Agostino and Senatore [20] and Han and Lee [21], among others.

Another important reason for the differences between predictions and experimental results is the effect of axial distortion of the cylinder liner or bore when in-situ. Hitherto, the works reported assume a constant radial out-of-roundness of the bore throughout the length of the cylinder. In practice the bore out-of-roundness differs along its length for a variety of reasons, including machining processes, assembly and structural means of stiffening, as well as 
Proceedings of the Institution of Mechanical Engineers, Part J: Journal of Engineering Tribology, 2012, Vol. 226, No. 4, pp. 284-305

(Accepted Version)

thermo-elastic distortion. Piao and Gulwadi [22] found that axial bore distortion had a significant effect on oil consumption, blow-by and friction.

Transient elastohydrodynamic analysis of the rough compression ring-cylinder liner conjunction for a high performance engine is considered in the current study. The analysis takes into account fitment of an incomplete circular ring into an out-of-round bore with different bore orders arising from machining, assembly and surface treatment. The most suitable ring-bore conformability analysis to agree with experimental measurements is chosen from among those with different mathematical basis suggested by Hill and Newman [3] and Tomanik [23]. The variable axial bore out-of-roundness is also taken into account. Hitherto, this approach in itself has not been reported in literature and is seen as being rather long overdue. The resulting analysis is quite realistic for an isothermal investigation of the problem, one which can be expanded in the future to include the effects of thermal shear thinning of the lubricant as well as ring dynamics when subjected to varying net forces in its in-plane and out-of-plane modal responses.

\section{Background Theory}

As already noted, the compression ring-cylinder liner conjunction is subject to a transient regime of lubrication. The prevailing conditions at any instant of time arise from a number of interacting phenomena. They include ring-bore conformance depending on ring tension, bore out-of-roundness and the cylinder pressure. Lubricant is entrained into the resulting gap through hydrodynamic action and pressurised to carry the contact load, in some instances this is shared with a proportion of load carried by asperity-pair interactions. Therefore, at any instant of time a simultaneous solution to a number of phenomena is required. A typical top compression ring/cylinder liner contact is shown schematically in Figure 1 in upstroke and downstroke motions of the piston inside the cylinder liner. 
Proceedings of the Institution of Mechanical Engineers, Part J: Journal of Engineering Tribology, 2012, Vol. 226, No. 4, pp. 284-305

(Accepted Version)

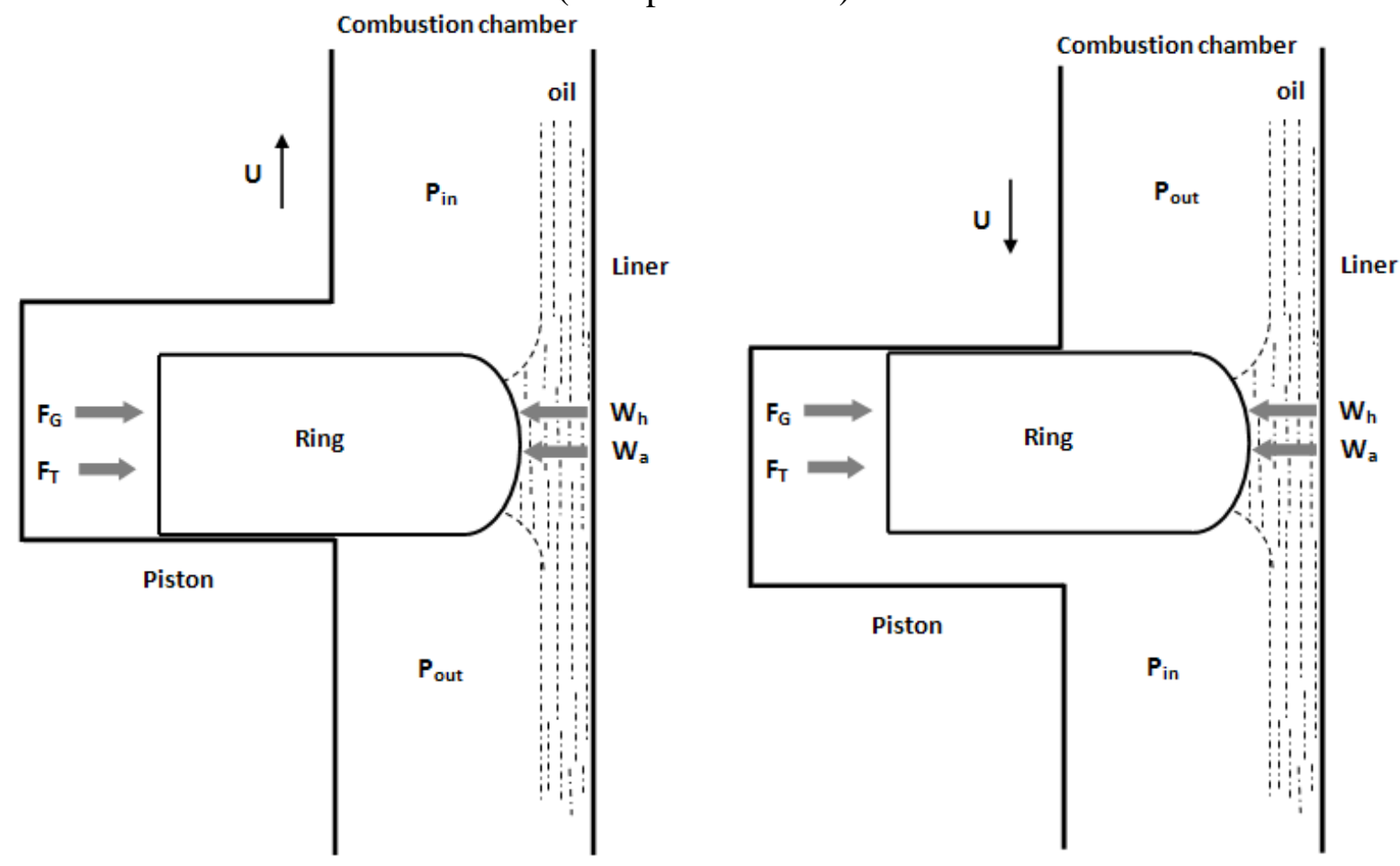

Figure 1: Schematic representation of top compression ring/cylinder liner contact in upstroke (left) and downstroke (right) motions

\section{1- Hydrodynamics}

Hydrodynamic flow in the compression ring-cylinder liner conjunction conforms to Reynolds equation. For a sliding contact [24]:

$\frac{\partial}{\partial x}\left[\left(\frac{\rho h^{3}}{6 \eta}\right) \frac{\partial p_{h}}{\partial x}\right]+\frac{\partial}{\partial y}\left[\left(\frac{\rho h^{3}}{6 \eta}\right) \frac{\partial p_{h}}{\partial y}\right]=\Delta U \frac{\partial}{\partial x}(\rho h)+2 \frac{\partial}{\partial t}(\rho h)$

where: $\Delta U=U_{1}-U_{2}$ and $U_{1}=0$ in this case.

It is assumed that the compression ring does not undergo any relative motion with respect to the piston sliding at the velocity $U_{2}$. In practice the ring may be subject to axial motion within its retaining groove; a motion termed as ring flutter. Thus [25]:

$U_{2}(\varphi)=-r \omega \sin \varphi\left\{1+\cos \varphi\left[\left(\frac{l}{r}\right)^{2}-\sin ^{2} \varphi\right]^{-\frac{1}{2}}\right\}$ 
Proceedings of the Institution of Mechanical Engineers, Part J: Journal of Engineering Tribology, 2012, Vol. 226, No. 4, pp. 284-305

(Accepted Version)

in which $\varphi$ is the crank-angle, $l$ the connecting rod length and $r$ is the crankpin radius.

Equation (1) assumes no side leakage flow in the $y$-direction (around the circumference of the ring, if envisaged as unwrapped). The following boundary conditions are used along the axial $x$-direction of the contact (i.e. along the ring face-width):

$$
\left\{\begin{array}{l}
p_{h}(0, y)=p_{U} \\
p_{h}(b, y)=p_{L} \\
p_{h}\left(x_{c}, y\right)=p_{c} \\
\left.\frac{d p_{h}(x, y)}{d x}\right|_{x=x_{c}}=0
\end{array}\right.
$$

where, the first two conditions correspond to the pressures at the lower and upper faces of the ring. These vary according to the sense of motion of the ring as well as the engine stroke. The lower two conditions define the oil film thickness rupture point, $x_{c}$ (Reynolds exit boundary condition, where cavitation occurs at the lubricant vaporisation pressure $p_{c}$ ). However, the analysis here does not include the effect of any cavitation region beyond the point of oil film rupture. A recent one dimensional analysis by Chong et al [26] investigates the effect of cavitation in some detail.

The compression ring is an incomplete circular ring with an end-gap of a few millimetres, when it is in its free state. When in-situ and within the cylinder and subjected to outward ring tension and combustion pressure, this end-gap is usually reduced to few tenths of millimetre. The pressure in the end gap is slightly different to that in the contact. To determine this, a blow-by gas analysis is required. Here, pressures at the edges of the gap are assumed to remain the same as those at its upper and lower faces, owing to the infinitesimal end gap. Thus: $p_{h}(x, 0)=p_{h}(x, L)$. 
Proceedings of the Institution of Mechanical Engineers, Part J: Journal of Engineering Tribology, 2012, Vol. 226, No. 4, pp. 284-305

(Accepted Version)

The lubricant bulk rheological state; viscosity and density are affected by pressure and temperature. For an isothermal solution only piezo-viscous behaviour of the lubricant needs to be considered. Therefore, according to Roelands [27]:

$\eta=\eta_{0} \exp \left(\alpha^{*} p_{h}\right)$

where:

$\alpha^{*}=\frac{1}{p_{h}}\left[\ln \left(\eta_{0}\right)+9.67\right]\left\{\left(1+\frac{p_{h}}{1.98 \times 10^{8}}\right)^{Z}-1\right\}$

and the pressure-viscosity index is:

$Z=\frac{\alpha_{0}}{5.1 \times 10^{-9}\left[\ln \left(\eta_{0}\right)+9.67\right]}$

The pressure-viscosity coefficient, $\alpha_{0}$, and the lubricant viscosity at atmospheric pressure $\eta_{0}$ are given in Table 1.

The density-pressure relationship is [28]:

$\rho=\rho_{0}\left[1+\frac{a\left(p_{h}-p_{a t m}\right)}{1+b\left(p_{h}-p_{a t m}\right)}\right]$

in which the constants $a$ and $b$ are $6.0 \times 10^{-10}$ and $1.7 \times 10^{-9}$ respectively and the atmospheric pressure, $p_{a t m}$, is $1.01325 \times 10^{5} \mathrm{~N} / \mathrm{m}^{2}$. The lubricant density at atmospheric pressure, $\rho_{0}$, is given in Table 1.

Table 1: Lubricant properties

\begin{tabular}{|c|c|c|}
\hline Parameter & Value & Unit \\
\hline pressure-viscosity coefficient & $1 \times 10^{-8}$ & $\mathrm{~m}^{2} / \mathrm{N}$ \\
\hline Lubricant density & $849.7 @ 15\left[{ }^{\circ} \mathrm{C}\right], 833.8 @ 40\left[{ }^{\circ} \mathrm{C}\right]$ & $\mathrm{kg} / \mathrm{m}^{3}$ \\
\hline Lubricant kinematic viscosity, $v$ & $59.99 @ 40\left[{ }^{\circ} \mathrm{C}\right], 9.590 @ 100\left[{ }^{\circ} \mathrm{C}\right]$ & $\times 10^{-6} \mathrm{~m}^{2} / \mathrm{s}$ \\
\hline
\end{tabular}


Proceedings of the Institution of Mechanical Engineers, Part J: Journal of Engineering Tribology, 2012, Vol. 226, No. 4, pp. 284-305

\section{2- Conjunctional geometry}

(Accepted Version)

To obtain the oil film thickness and the corresponding pressure distribution at any instant of time (i.e. at any crank angle $\varphi$ ), a simultaneous solution of Reynolds equation with a film shape expression is needed. Mishra et al [16-17] state the elastic film shape as:

$h(x, y, t)=h_{m}(t)+h_{s}(x)+\Delta(y, t)+\delta(x, y, t)$

where the film thickness at any instant of time depends on the nominal or minimum clearance $h_{m}$, the ring axial profile $h_{s}$ (along its face-width in the $x$ direction) and its elastic deflection. The overall deflection comprises two components; $\Delta$, termed as global deflection at any circumferential location and $\delta$; the localised contact pressure-induced deflection. The former is because of large strain deformation in ring shape due to the elastic ring tension force and the prevailing combustion pressure acting at any instant of time behind the ring inner face, pushing it towards the bore surface. As noted, the latter is the localised small strain deformation, $\delta$ arising as the result of generated lubricant pressures in the ring-bore conjunction. This is analogous to the contact deflection in concentrated contacts under high load. Mishra et al [16] showed that this component of deflection is actually quite small, as the generated pressures are usually insufficient to cause localised deformation, except at quite high combustion pressures.

Equation (8) ignores any thermo-elastic deformation of the cylinder liner as well as dynamic modal response of the ring, when subjected to variations in the net force applied to it.

\section{(a)- Axial ring profile}

As in all tribological conjunctions the axial profile of the compression ring plays an important role in the entrainment of a film of lubricant into the conjunction, mainly by the inlet wedge 
Proceedings of the Institution of Mechanical Engineers, Part J: Journal of Engineering Tribology, 2012, Vol. 226, No. 4, pp. 284-305

(Accepted Version)

effect [29]. Therefore, it is customary to furnish the ring with profiled edges along its facewidth. These are usually small relief radii or chamfers. The central land along the ring facewidth, between its relieved edges, is nominally flat in its unworn state and due to its proximity with the bore surface, is usually coated with a wear resistant layer. The ring studied here is a steel ring with a chamfer at its upper face and a relief radius at its lower face. The central portion of the ring face-width is furnished with a low friction chromium sputtered coating.

In tribological analysis of compression rings various idealised face-width geometries have been considered in the literature. It is quite customary to assume a symmetrical parabolic axial profile, for example by Dowson et al [6], Arcoumanis et al [30], Bolander et al [19], Mishra et al [16-17] and Mufti et al [31]. Other research workers such as Ma et al [15] and Akalin and Newaz [12-13] have used a profile with a central flat land. In either case the results would represent specific conditions. For example, those with an unworn profile are representative of conditions encountered during initial wear phase of the ring face. This can be very short lived, depending on the engine running-in conditions. Those assuming a symmetrical parabolic ring axial profile are representative of idealised worn rings. In practice, the relief features provided at the edges of the ring face-width differ as tribological conditions are dissimilar in upstroke and down-stroke senses of the piston. Therefore, a nonsymmetric (skewed) parabolic ring face profile is often noted of embedded worn rings.

A new and a used (worn) ring face-width axial profiles were measured using an optical Talysurf profilometer with a measurement sensitivity of $\pm 1 \mu \mathrm{m}$. These are shown in Figure 2 . Note that neither of the rings conforms to a parabolic profile, which is often used as ideal for analysis of the ring-bore contact. A polynomial of order of six fits well to the measured geometry. 
Proceedings of the Institution of Mechanical Engineers, Part J: Journal of Engineering Tribology, 2012, Vol. 226, No. 4, pp. 284-305

(Accepted Version)

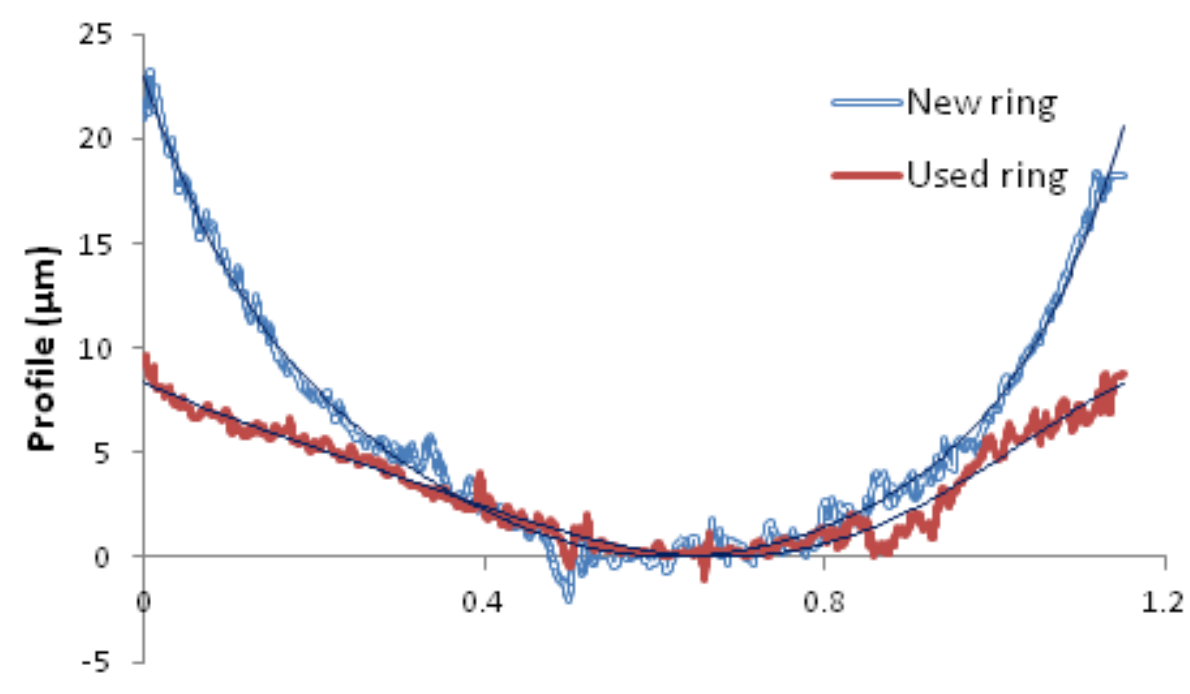

Distance along the face-width (mm)

Figure 2: Measured new and used ring face-width profile

The measurements were taken at several locations along the ring periphery and averaged, before a polynomial fit was made. It should be noted that in practice with an out-of-round bore, both radially and axially, subjected to thermo-elastic distortion and with the transient nature of the contact, the wear of ring face-width can be quite uneven along its periphery. Ideally, a three-dimensional ring face-width geometry should be accounted for. However, the current analysis is still far more realistic than the usually assumed parabolic shape. The polynomial equation describing the measured new ring axial profile is:

$h_{s}(x)=427.9 x^{6}-1455.8 x^{5}+1971.4 x^{4}-1354.4 x^{3}+544.57 x^{2}-150.49 x+25.30$

Likewise, the polynomial equation describing the measured worn ring profile is:

$h_{s}(x)=-6.493 x^{6}-49.845 x^{5}+143.22 x^{4}-98.541 x^{3}+27.351 x^{2}-17.338 x+7.4986$

It should be noted that in these two equations the units for $x$ and $h_{s}$ are $\mathrm{mm}$ and $\mu \mathrm{m}$ respectively. 
Proceedings of the Institution of Mechanical Engineers, Part J: Journal of Engineering Tribology, 2012, Vol. 226, No. 4, pp. 284-305

(Accepted Version)

\section{(b)- Ring global deformation and conformation to an out-of-round bore}

Aside from the axial profile of the ring face-width, its radial profile whilst in-situ and subject to ring tension and combustion gas force acting behind its inner peripheral face-width at any instant of time is required as indicated by equation (8). The radial global deformation of the ring, $\Delta$ subjected to these forces is calculated from a conformability analysis, according to ring's mechanical properties and the geometrical constraining effect of an out-of-round bore. The conformability of the ring to bore/liner surface is critical in its sealing functional performance.

The cylinder bore can in fact take a relatively complex form. There are three main factors determining the exact cylinder bore geometry. These are the distortions arising from dynamic (mechanical) forces present when an engine is running, including the combustion gas forces, piston slap, etc. In this case, the nature of the distortions is transient. The second factor is the bore thermal distortion. This also has a transient nature [32]. The third form of distortion has a static nature. It can be attributed to inherent imperfections in attempting to manufacture a perfect right circular cylinder as well as imperfections introduced during machining processes (for example as a result of vibrations), and distortions caused by the fitment process of the liner into the cylinder block and the mounting of other components such as the cylinder head [23, 33]. As a result, the piston-ring/cylinder liner conjunction can take a very complex form.

Figure 3 is a schematic representation of various bore orders, $n$ referring to its out-ofroundness representation by $n$ lobes. $n=0$ corresponds to changes in the cylinder diameter which is usually considered as unimportant when dealing with piston ring performance. The order one is representative of an existing eccentricity between the axis of the measuring system and that of the cylinder liner. These distortions are controllable for a given engine [3]. 
Proceedings of the Institution of Mechanical Engineers, Part J: Journal of Engineering Tribology, 2012, Vol. 226, No. 4, pp. 284-305

(Accepted Version)

Other bore orders, $n \geq 2$ are associated with cylinder out-of-roundness, caused by the machining imperfections (ovality: order of 2 is due to boring of the cylinder) and distortions originated from tightening of the cylinder head bolts $(n=4)$ [3]. Minimising these distortions is of interest for engine designers.

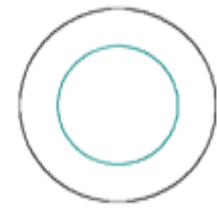

$\mathrm{n}=0$

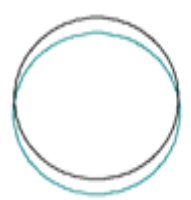

$n=1$

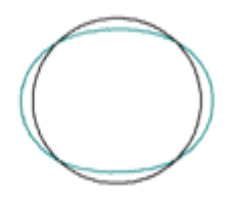

$n=2$

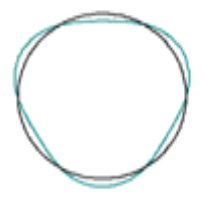

$n=3$

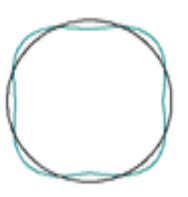

$n=4$

Figure 3: Typical distorted bore forms for the first few bore orders

In addition to the bore elastic deformations, a more realistic model should also include the dynamics of the compression ring itself, when subjected to a net force arising from ring tension, gas pressure and the contact force. It is well known that the compression ring undergoes complex dynamic distortions including in its radial plane (in-plane) and out-ofplane motions. The current study focuses on the distortions of static nature, which is suitable for the isothermal analysis undertaken here.

The cylinder liner profile, in-situ in the bore of the engine under investigation, was measured at several axial cross-sections along its length using a Coordinate Measuring Machine (CMM), with an accuracy of $\pm 1.5 \mu \mathrm{m}$ on any measured diameter. The measured profiles in unwrapped form at various cross-sections along the bore are shown in Figure 4. Changes in the profile are representative of bore axial distortion. 
Proceedings of the Institution of Mechanical Engineers, Part J: Journal of Engineering Tribology, 2012, Vol. 226, No. 4, pp. 284-305

(Accepted Version)

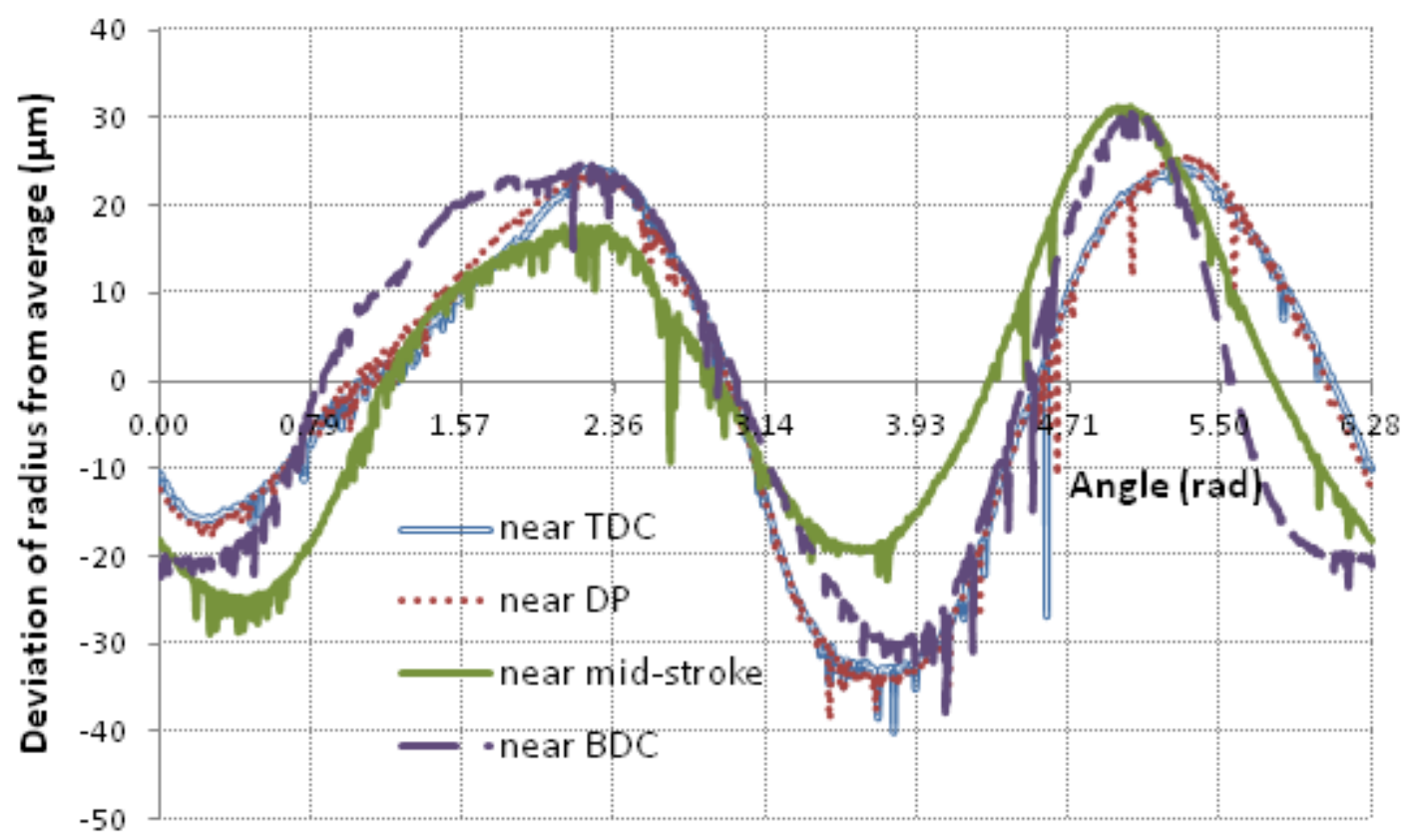

Figure 4: Deviation of the liner from a perfect right circular cylinder at different axial cross-sections

Ideally, the compression ring would deform in order to conform to these various liner crosssections. However, in practice, the ring would only partially accommodate these changes in profile. The degree of conformance is limited by the ring elastic properties, the constraining geometry and the instantaneous applied forces. Therefore, at any axial step in the ring motion, at any (circumferential) point where the ring fails to conform to the given bore shape, a gap would ensue.

There have been various proposed methods to estimate the ring-bore gap. These are usually based on analytical or semi-empirical approaches. For example, Ma et al [15] use Hill and Newman's criterion [3] amongst the others, such as Bardzimashvili et al [33] to calculate the ring-bore gap conformance. Hu et al [18] take a different approach by assuming a linear relationship between the applied forces and the resultant deformations. An analysis of the ring-bore gap using the bounds for the maximum allowable deformation is only applicable 
Proceedings of the Institution of Mechanical Engineers, Part J: Journal of Engineering Tribology, 2012, Vol. 226, No. 4, pp. 284-305

(Accepted Version)

for a given bore order. However, as Bardzimashvili, et al [33] suggest, a multiple order deformation analysis can be conducted which would be more accurate and should be considered for gap analysis. In the current study, the dominant bore order is ascertained through measurement and used in order to reduce the complexity of the multiple-order calculations.

From the measurements, the distorted bore profile at any axial cross-section can be expressed as:

$\xi(\theta)=r_{0}+\Delta r(\theta)$

where, $\Delta r$ is the vector of deviations from the nominal radius of the bore (as shown in Figure 4). These distortions can be expressed using a Fourier series [15, 23, 34]:

$\Delta r(\theta)=\sum_{n=0}^{N}\left[A_{n} \cos (n \theta)+B_{n} \sin (n \theta)\right]$

where, $\theta$ denotes polar angles at which the measurements have taken place, $n$ is the bore order and $A_{n}$ and $B_{n}$ are the Fourier coefficients.

The maximum radial distortion at any order, $n$, and the angle at which this distortion takes place are computed as [34, 35]: $\left(u_{\max }\right)_{n}=\sqrt{A_{n}^{2}+B_{n}^{2}}$ and $\theta_{n}=\frac{1}{n} \tan ^{-1}\left(\frac{B_{n}}{A_{n}}\right)$.

The latter is a representative angle between the axis which passes through the point of maximum deformation and the horizontal axis of the measuring coordinate system.

Using these notations, equation (12) can be rewritten as [34]:

$\Delta r(\theta)=\sum_{n=0}^{N}\left\{\frac{\left(u_{\max }\right)_{n}}{2} \cos \left[n\left(\theta-\theta_{n}\right)\right]\right\}$ 
Proceedings of the Institution of Mechanical Engineers, Part J: Journal of Engineering Tribology, 2012, Vol. 226, No. 4, pp. 284-305

(Accepted Version)

In order to determine the dominant bore order, fast Fourier analysis of measured bore profile is, therefore, undertaken.

A conformability coefficient is generally defined as: $K=\frac{F_{T} r_{0}^{2}}{E I}$ in which the term $E I$ is the ring flexural rigidity and for a ring of rectangular cross-section: $I=\frac{1}{12} b d^{3}$, where, $b$ is the ring face-width and $d$ is its thickness. For most rings the conformability coefficient varies between 0.01 and 0.04 [23].

The conformability of the ring to the liner improves in a fired engine, because of combustion gas force acting behind its inner peripheral face, enhancing the outward radial force on the ring. There is some debate as to the proportion of gas force which may act behind the ring. If, for simplicity one would assume that the entire gas force is taken into account, then [15]:

$F_{G}(\theta)=p_{g b}(\theta) b r_{0}$

and therefore, the modified conformability coefficient becomes:

$K(\theta)=\frac{\left[F_{T}+F_{G}(\theta)\right] r_{0}^{2}}{E I}$

In fact the ring can only accommodate a certain maximum deformation (out-of-roundness of the liner), whilst still retaining its sealing function. Taking this issue into account, Bardzimashvili et al [34] state that: $u_{n}(\theta)=\frac{K(\theta) r_{0}}{\left(n^{2}-1\right)^{2}}$. This is known as the GOETZE bound in the literature. This relationship can also be obtained through an analytical observation, for example as shown by Bardzimashvili et al [34]. However, a semi-empirical study by Tomanik [23] suggests the best criterion to use would be:

$u_{n}(\theta)=\frac{K(\theta) r_{0}}{20\left(n^{2}-1\right)}$ 
Proceedings of the Institution of Mechanical Engineers, Part J: Journal of Engineering Tribology, 2012, Vol. 226, No. 4, pp. 284-305

(Accepted Version)

On the other hand, Hill and Newman [3] have suggested the following bound from their experimental observations:

$u_{n}^{\prime}(\theta)=\frac{K^{\prime}(\theta) r_{0}}{4\left(n^{2}-1\right)^{2}}$

in which the conformability factor, $K^{\prime}$ is defined as:

$K^{\prime}(\theta)=\frac{\left[F_{T}+F_{G}(\theta)\right]\left(2 r_{0}-d\right)^{2}}{E I}$

and $d$ is the ring thickness.

It should be noted that other criteria for the ring-bore conformability are also proposed, for example by Dunaevsky [34]. The current study uses the bounds proposed by Hill and Newman [3] and Tomanik [23] as two alternatives.

The gap that an in-situ ring makes with an out-of-round bore at any instant of time can thus be obtained as [15]:

$G(\theta)=\max \left\{0,\left[\Delta r(\theta)-\Delta r_{\min }\right]-u_{n}(\theta)\right\}$

The obtained gap, $G$ at any peripheral angle, $\theta$ can then be transformed to the Cartesian coordinate set in order to determine $\Delta$, required for equation (8).

\section{(c)- Localised contact deformation}

Pressure generated by the entrained lubricant into the ring-bore conjunction may be sufficient to cause localised deformation of contiguous surfaces as well as promote piezo-viscous conditions. Generally, in partially conforming ring-bore contact, the generated pressures have been found to be insufficient to promote elastohydrodynamic conditions. However, the 
Proceedings of the Institution of Mechanical Engineers, Part J: Journal of Engineering Tribology, 2012, Vol. 226, No. 4, pp. 284-305

(Accepted Version)

chance of this should not be precluded in any detailed analysis. Dowson et al [6] and Akalin and Newaz [12-13] report one dimensional line contact analyses, which essentially assumes a counterformal contact of a parabolic ring face-width against a bore surface of an infinite radius of curvature. Two-dimensional analyses, for example by Ma et al [15] and Mishra et al [16-17] are based on a conforming ring in circumferential direction and non-conforming in the axial direction. Generated pressures are more realistic for such partially conforming contacts of fairly large contact footprint. Mishra et al [16-17] show that the generated pressures are insufficient to either cause any significant piezo-viscous action of the lubricant or indeed localised deflection of the contiguous surfaces, even for their high performance racing engine with high combustion pressures and very thin ring face-width. However, due to the out-of-roundness of the bore, the circumferential gap may vary greatly and thus certain conjunctional regions can be subject to disproportionately large pressures, particularly with high combustion pressures encountered with such high performance engines as that in the current study.

The localised deformation at any point in the contact, subject to an arbitrary generated pressure is found through solution of the elasticity potential integral:

$\delta(x, y)=\frac{1}{\pi E^{\prime}} \int_{0}^{L} \int_{0}^{b} \frac{p_{h}\left(x_{1}, y_{1}\right) d x_{1} d y_{1}}{\sqrt{\left(x-x_{1}\right)^{2}+\left(y-y_{1}\right)^{2}}}$

in which, the reduced (equivalent) elasticity modulus, $E^{\prime}$, is obtained as: $\frac{2}{E^{\prime}}=\frac{1-v^{2}}{E}+\frac{1-v_{l}^{2}}{E_{l}}$.

The integration in the above equation can be represented in a discretised form as:

$\delta(x, y)=\frac{2 p_{h}}{\pi E^{\prime}} D^{*}$

where $D^{*}$ is an influence coefficient matrix [36-37]. 
Proceedings of the Institution of Mechanical Engineers, Part J: Journal of Engineering Tribology, 2012, Vol. 226, No. 4, pp. 284-305

\section{3- Forces acting on the ring}

(Accepted Version)

\section{(a)- Radial in-plane forces:}

In its radial plane, the ring is subjected to two outward forces; ring tension or elastic force $F_{T}$ and the gas force $F_{G}$. These forces, as noted above, strive to conform the ring to the bore surface. Thus, the total outward force on the ring is: $F=F_{T}+F_{G}$. The ring tension force is obtained as: $F_{T}=p_{e} b r_{0}$, where the elastic pressure $p_{e}$ is [38]:

$p_{e}=\frac{g E I}{3 \pi b r_{0}^{4}}$

where $g$ is the ring end gap in its free state.

The gas force acting behind the ring's inner face is given by equation (14). The combustion pressure varies with engine speed and throttle demand. Figure 5 shows a typical combustion curve for the engine speed of 2000 rpm with $63 \%$ throttle.

These outward forces are opposed by the contact force generated as the result of combined actions of generated conjunctional hydrodynamic pressures and the load share carried by direct contact of surfaces themselves. The latter is often the load shared by a small portion of asperities on the opposing surfaces. Thus, the instantaneous contact load is determined as: $W=W_{a}+W_{h}$, where the load carried by any film of lubricant is the integrated pressure distribution: $W_{h}=\int_{0}^{L} \int_{0}^{b} p_{h} d x d y$. 
Proceedings of the Institution of Mechanical Engineers, Part J: Journal of Engineering Tribology, 2012, Vol. 226, No. 4, pp. 284-305

(Accepted Version)

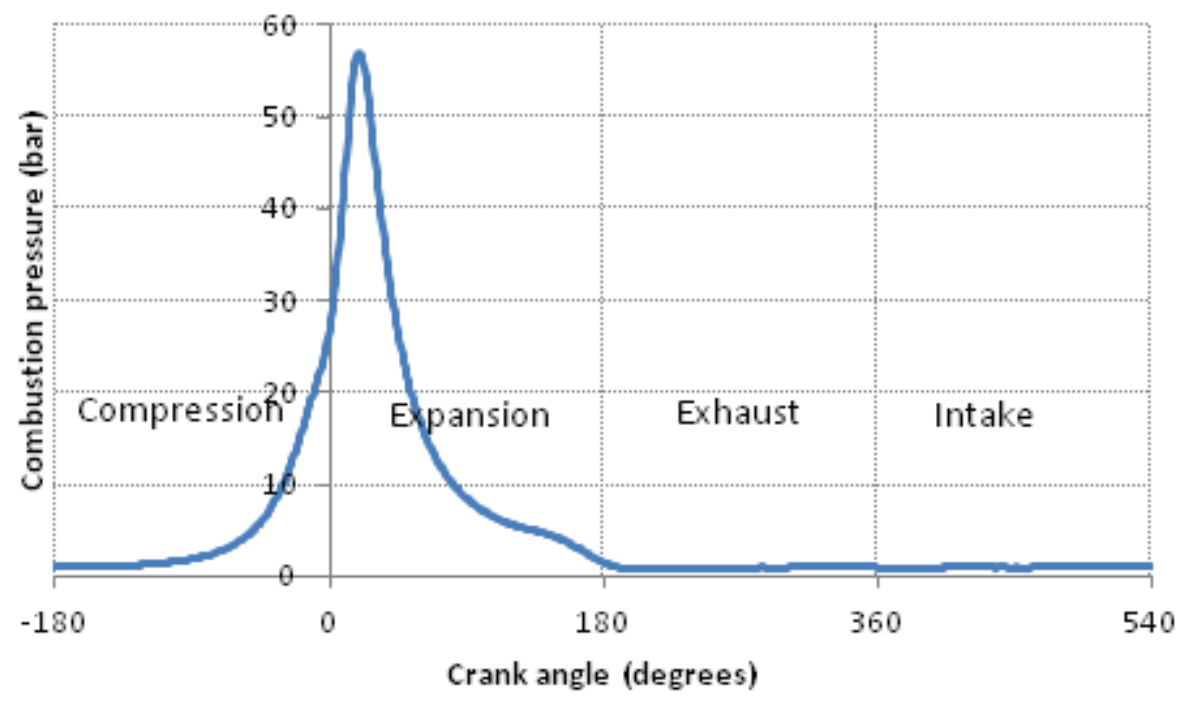

Figure 5: Variation of the pressure inside the combustion chamber with crank angle at engine speeds of 2000rpm

The share of load carried by the asperities is obtained as [39]:

$W_{a}=\frac{8 \sqrt{2}}{15} \pi(\zeta \kappa \sigma)^{2} \sqrt{\frac{\sigma}{\kappa}} E^{\prime} A F_{5 / 2}(\lambda)$

The dimensionless group $\zeta \kappa \sigma$ is known as the roughness parameter, whilst $\sigma / \kappa$ is a measure of a typical asperity slope. These can be obtained through topographical measurements.

The statistical function $F_{5 / 2}(\lambda)$ is introduced to match the assumed Gaussian distribution of asperities as a function of the Stribeck oil film parameter, $\lambda=\frac{h(x, y)}{\sigma}$ :

$F_{j}(\lambda)=\frac{1}{2 \pi} \int_{\lambda}^{\infty}(s-\lambda)^{j} \exp \left(-\frac{s^{2}}{2}\right) d s$

In order to make this function amenable to simple computation, two different approaches are proposed. The first is due to Hu et al [18], using a non-linear curve as: 
Proceedings of the Institution of Mechanical Engineers, Part J: Journal of Engineering Tribology, 2012, Vol. 226, No. 4, pp. 284-305

$F_{5 / 2}(\lambda)= \begin{cases}A(\Omega-\lambda)^{Z} & ; \lambda \leq \Omega \\ 0 & ; \lambda>\Omega\end{cases}$

(Accepted Version)

in which $\Omega=4.0, A=4.4068 \times 10^{-5}$ and $z=6.804$. In fact, by choosing $\Omega=4$, Hu et al [18] extended the upper limit for the mixed regime of lubrication from the usual value of $\lambda=3$ to $\lambda=4$.

The alternative relationship uses a fifth order polynomial curve fit to represent equation (24) for $j=1[40]$ :

$F_{5 / 2}(\lambda)=-0.0046 \lambda^{5}+0.0574 \lambda^{4}-0.2958 \lambda^{3}+0.7844 \lambda^{2}-1.0776 \lambda+0.6167, \quad$ where $F_{5 / 2}(\lambda)>0$.

A quasi-static analysis, disregarding inertial or modal in-plane dynamics of the ring, demands the balance of the outward applied forces with the contact reaction, $W=W_{h}+W_{a}$. This is the approach undertaken in each instant of contact (i.e. at any crank angle). The transient dynamic analysis, on the other hand, would take into account the aforementioned ring dynamics, which is a function of the instantaneous minimum clearance, thus: $F-W=$ $m \frac{\partial^{2} h_{m}(t)}{\partial t^{2}}$. This would lead to considerably longer computations, but would retain the time history of the ring inertial motion, as well as any of its structural modal behaviour. Piao and Gulwadi [22] highlight such an approach, but with the drawbacks of one dimensional hydrodynamic analysis and with obviously no need for ring-bore conformability study. Hence, inertial or "floating" motion of the ring is not accounted for in the quasi-static approach.

Tables 2 and 3 list the material properties as well as the surface topographical parameters for both the compression ring and the liner samples used in this analysis. 
Proceedings of the Institution of Mechanical Engineers, Part J: Journal of Engineering Tribology, 2012, Vol. 226, No. 4, pp. 284-305

(Accepted Version)

Table 2: Ring and liner material properties

\begin{tabular}{|c|c|c|}
\hline Parameter & Value & Unit \\
\hline Liner material & Grey cast iron & $\mathrm{GPa}$ \\
\hline Modulus elasticity of liner material & 92.3 & - \\
\hline Poisson ratio for liner material & 0.211 & $\mathrm{GPa}$ \\
\hline Ring material & Steel SAE 9254 & - \\
\hline Modulus elasticity of ring material & 203 & 0.3 \\
\hline Poisson ratio for ring material & & \\
\hline
\end{tabular}

Table 3: Ring and liner surface topographical parameters

\begin{tabular}{|c|c|c|}
\hline Parameter & Value & Unit \\
\hline Ra for liner & 0.26 & $\mu \mathrm{m}$ \\
\hline Rk for liner & 0.298 & $\mu \mathrm{m}$ \\
\hline Ra for new ring & 0.408 & $\mu \mathrm{m}$ \\
\hline Rk for new ring & 1.32 & $\mu \mathrm{m}$ \\
\hline Ra for worn ring & 0.235 & $\mu \mathrm{m}$ \\
\hline Rk for worn ring & 0.585 & $\mu \mathrm{m}$ \\
\hline Roughness parameter $(\zeta \kappa \sigma)$ & 0.167 & - \\
\hline Measure of asperity gradient $(\sigma / \kappa)$ & $2.034 \times 10^{-3}$ & - \\
\hline
\end{tabular}

\section{(b)- Friction and power loss}

At any instant of time, viscous shear of a film of lubricant, $h$ is obtained as [29]:

$\vec{\tau}=\left| \pm \frac{h}{2} \vec{\nabla} p-\Delta \vec{V} \frac{\eta}{h}\right|$, where the gradient $\vec{\nabla} \equiv\left(\frac{\partial}{\partial x} \hat{\imath}+\frac{\partial}{\partial y} \hat{\jmath}\right)$. If this shear stress is below the limiting Eyring [41] shear stress of the lubricant used; $\tau_{0}=2 \mathrm{MPa}$ (in this case), then the lubricant follows a Newtonian shear behaviour, and friction is obtained as: $f_{t}=f_{v}=\tau A$ where $A$ is the contact area. 
Proceedings of the Institution of Mechanical Engineers, Part J: Journal of Engineering Tribology, 2012, Vol. 226, No. 4, pp. 284-305

(Accepted Version)

Under the mixed elastohydrodynamic analysis and at high shear, the lubricant film is usually quite thin and subject to non-Newtonian traction $(\tau>\tau)$ ). The total friction is, therefore, because of viscous shear of the lubricant and boundary contribution due to asperity interactions on the contiguous surfaces: $f_{t}=f_{v}+f_{b}$

The boundary friction is obtained as [39]:

$f_{b}=\tau_{0} A_{a}+\varsigma W_{a}$

$\varsigma$ is the pressure coefficient for boundary shear strength of asperities on the softer counterface, in this case: $\varsigma=0.17$ [40]. In addition, the cumulative area of asperity tips, $A_{a}$, is found as [39]:

$A_{a}=\pi^{2}(\zeta \kappa \sigma)^{2} \sqrt{\frac{\sigma}{\kappa}} A F_{2}(\lambda)$

$F_{2}(\lambda)$ is a function representative of the Gaussian distribution of asperities in terms of the Stribeck’s oil film parameter, $\lambda$ :

$$
F_{2}(\lambda)=-0.0018 \lambda^{5}+0.0281 \lambda^{4}-0.1728 \lambda^{3}+0.5258 \lambda^{2}-0.8043 \lambda+0.5003
$$

The viscous friction force, $f_{v}$ is obtained as [40]:

$f_{v}=\tau\left(A-A_{a}\right)$

The total power loss from ring-bore conjunction is because of both viscous and boundary friction. The contribution due to viscous friction is [42]:

$$
P_{f v}=\int_{0}^{L} \int_{0}^{b}\left(\frac{h^{3}}{12 \eta}|\vec{\nabla} p|^{2}+\frac{\eta}{h} \Delta \vec{V}^{2}\right) d x d y
$$


Proceedings of the Institution of Mechanical Engineers, Part J: Journal of Engineering Tribology, 2012, Vol. 226, No. 4, pp. 284-305

The power loss due to boundary friction is:

(Accepted Version)

$P_{f b}=f_{b}|\Delta U|$

Therefore, the total frictional loss is: $P_{f}=P_{f b}+P_{f v}$

\section{Method of solution}

Reynolds equation is discretised using finite differences. Since the density, viscosity and local deflections are functions of generated pressure, which itself has spatial distribution, their variations are also considered in the discretisation process:

$\frac{\partial \Psi_{\mathrm{i}}}{\partial x_{k}}=\left(\frac{\partial \Psi_{\mathrm{i}}}{\partial p}\right)\left(\frac{\partial p}{\partial x_{k}}\right) \quad ;\left\{\begin{array}{l}i=1,2,3 \\ k=1,2\end{array}\right.$

in which $\Psi_{1}=\rho, \Psi_{2}=\eta, \Psi_{3}=\delta$ and $x_{1}=x, x_{2}=y$.

After combining the above derivatives in the Reynolds equation and using a central difference for the second order pressure differentials, pressure at each computational node is defined as:

$p_{i, j}=\frac{A_{i, j}+Q_{i, j}\left(p_{x}^{2}+p_{y}^{2}\right)+3\left(M_{i, j} p_{x}+N_{i, j} p_{y}\right)-6 R_{i, j}}{2\left(\frac{1}{\Delta x^{2}}+\frac{1}{\Delta y^{2}}\right)}$

where: $p_{x}=\frac{\partial p}{\partial x}=\frac{p_{i+1, j}-p_{i-1, j}}{2 \Delta x}$ and $p_{y}=\frac{\partial p}{\partial y}=\frac{p_{i, j+1}-p_{i, j-1}}{2 \Delta y}$.

The other terms in equation (32) are provided in Appendix A.

Pressure at any computational node $(i, j)$ is obtained through Point Successive OverRelaxation (PSOR) iterative method [43]. The pressure for each node is updated using under/over-relaxation concept: 
Proceedings of the Institution of Mechanical Engineers, Part J: Journal of Engineering Tribology, 2012, Vol. 226, No. 4, pp. 284-305

(Accepted Version)

$p_{i, j}^{n}=(1-\gamma) p_{i, j}^{n-1}+\gamma p_{i, j}^{n} \quad ;(0<\gamma<2)$

Determining the relaxation factor, $\gamma$, is problem dependent and the optimum value which provides the fastest solution is usually obtained after some numerical tests [43]. For the current problem an over-relaxation factor of 1.78 was found to be the optimum.

\section{1- Convergence criteria}

A two-stage convergence process is sought. Firstly, the generated pressures and lubricant rheological states are deemed to have converged, when:

$\operatorname{Err}_{\text {pressure }}=\frac{\sum_{i=1}^{I} \sum_{j=1}^{J}\left|p_{i, j}^{n}-p_{i, j}^{o}\right|}{\sum_{i=1}^{I} \sum_{j=1}^{J} p_{i, j}^{n}} \leq 1 \times 10^{-5}$

And:

$E r r_{\text {properties \& deflection }}=\frac{\sum_{i=1}^{I} \sum_{j=1}^{J}\left|\Psi_{i, j}^{n}-\Psi_{i, j}^{o}\right|}{\sum_{i=1}^{I} \sum_{j=1}^{J} \Psi_{i, j}^{n}} \leq 1 \times 10^{-3}$

Secondly, the aforementioned quasi-static balance of applied forces on the ring is sought through:

$\operatorname{Err}_{\text {load }}=\frac{|F(\varphi)-W(\varphi)|}{F(\varphi)} \leq 1 \times 10^{-3}$

If this criterion is not met then the minimum nominal gap is adjusted and the entire iterative procedure is repeated:

$h_{m}^{n}=(1+\beta \chi) h_{m}^{o}$ 
Proceedings of the Institution of Mechanical Engineers, Part J: Journal of Engineering Tribology, 2012, Vol. 226, No. 4, pp. 284-305

(Accepted Version)

$\chi$ is an adjusting parameter: $\chi=\frac{W(\varphi)-F(\varphi)}{\max \{W(\varphi), F(\varphi)\}}$. Superscripts $n$ and $o$ denote new and old steps in the iteration process. A damping coefficient, $\beta=0.05$ is used to effect faster load convergence, whilst avoiding numerical instability.

Finally, a typical analysis cycle requires an initial guess as the nominal minimum clearance. This means that the analysis should continue until cyclic behaviour in minimum clearance is achieved between successive engine cycles. Thus:

$\operatorname{Err}_{\text {clearance }}=\frac{\left|h_{m}(\varphi)-h_{m}(\varphi-720)\right|}{h_{m}(\varphi-720)} \leq 1 \times 10^{-3}$

The computational mesh contained $100 \times 64$ nodes and typical simulation time varied between 5 to 6 hours for most cases.

\section{Results and Discussion}

In order to determine the dominant bore order, Fourier transformations of the measured liner profiles is carried out (Figure 6). The spectra of run-out of circularity at the various indicated cross-sections reveal the dominance of ovality $(n=2)$ of the liner cross-sections. However, bore orders of 3 and to a lesser extent 4 are also significant. 
Proceedings of the Institution of Mechanical Engineers, Part J: Journal of Engineering Tribology, 2012, Vol. 226, No. 4, pp. 284-305

(Accepted Version)

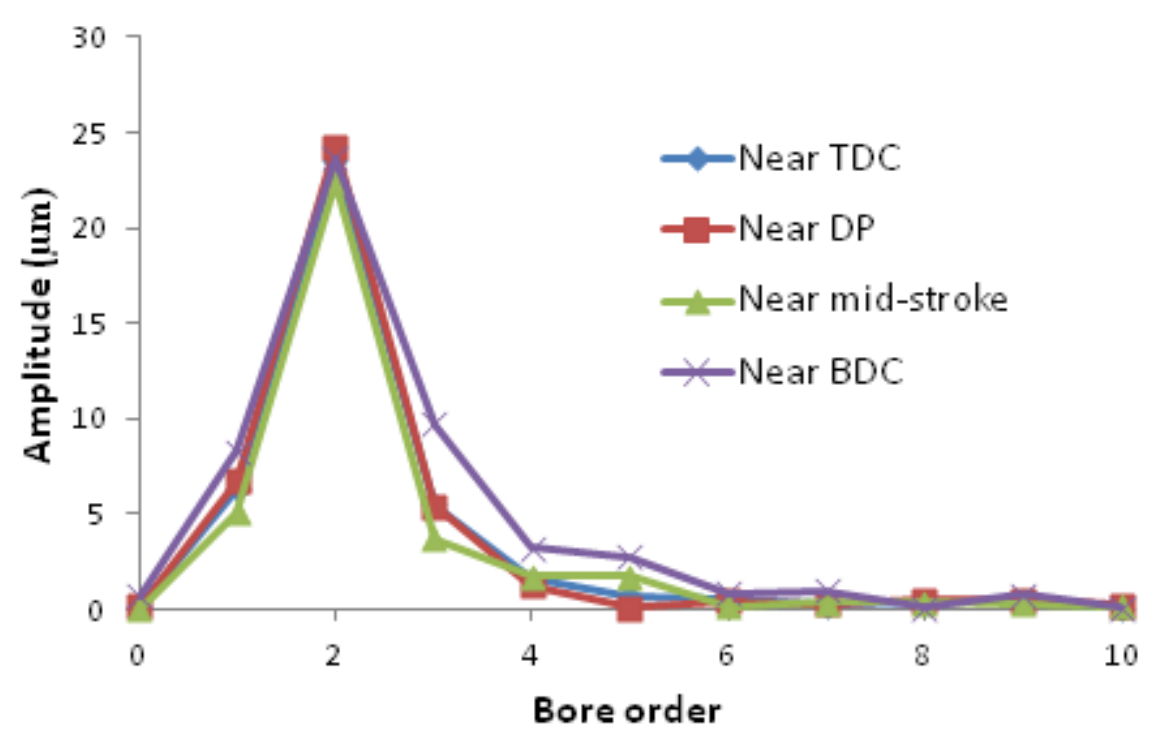

Figure 6: Spectral contributions of cross-sectional run-out of circularity

Both Hill and Newman [3] and Tomanik [23] methods for ring-bore conformability are used throughout the engine cycle, taking into account bore cross-sectional variation and the applied gas pressure from Figure 5. The results of these analyses are shown in Figure 7. In fact, the Hill and Newman bounds predict complete ring-bore conformance for an oval bore. The implication is that ring tension and gas pressure would be sufficient to produce a lighttight seal. Thus, any non-conformance would be as the result of distortions of $3^{\text {rd }}$ and $4^{\text {th }}$ order. Figure 7(a) shows predictions based on the Hill and Newman method for the case of $n=3$. In reality out-of-roundness caused by manufacturing and surface treatment of the liner (i.e. $n=3)$ and assembly/fitment of cylinder head $(n=4)$ render mere partial conformance, which improves with high gas pressures in parts of the compression stroke (in the vicinity of the top dead centre) and in the power stroke (i.e. approximately through $-90^{\circ} \leq \varphi \leq 180^{\circ}$ ). Using Tomanik’s bound, Figure 7(b) for $n=3$, a ring-liner gap is noted for most of the engine cycle, except for the high pressure region of the power stroke and for a shorter portion of the compression stroke in the vicinity of the top dead centre. 
Proceedings of the Institution of Mechanical Engineers, Part J: Journal of Engineering Tribology, 2012, Vol. 226, No. 4, pp. 284-305

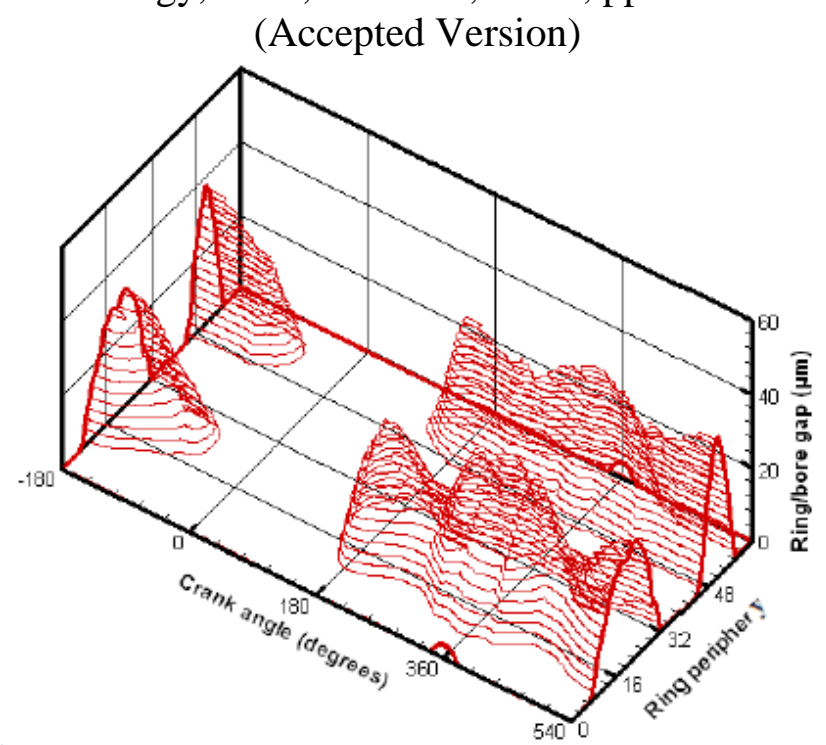

(a)- Hill and Newman (1985) bounds

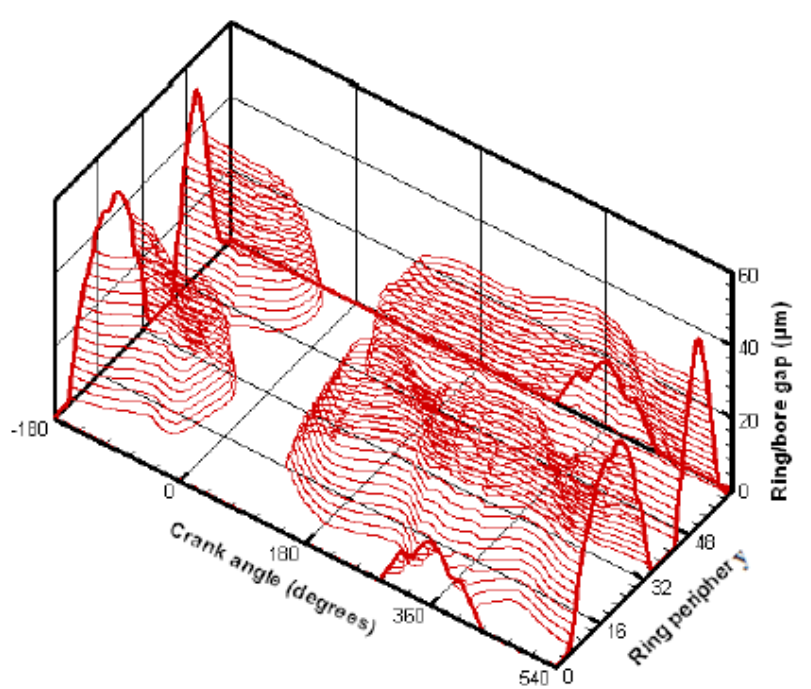

(b)- Tomanik (1996) bounds

Figure 7: Ring conformance to out-of-round bore subject to ring tension and gas pressure throughout the 4-stroke engine cycle

There are clearly differences between the measurement-based empirical Hill and Newman [3] approach and the semi-analytical method of Tomanik [23]. As already noted, the bore shape comprises contributions from all bore orders $n$, which clearly would affect each other. Thus, 
Proceedings of the Institution of Mechanical Engineers, Part J: Journal of Engineering Tribology, 2012, Vol. 226, No. 4, pp. 284-305

(Accepted Version)

empirical methods such as that by Hill and Newman [3] are best used with multi-order bore analyses. They also depend on the accuracy of measurements and in-situ conditions used. Although the findings of both approaches largely agree with each other, use of an analytical method such as that of Tomanik [23], whilst theoretical, would be preferred because they are subject to no extraneous sources of inaccuracy such as the chosen method of measurement. The important finding of either approach; empirical or analytical, is that significant gaps exist in the ring-liner conjunction. There are clearly repercussions for lubricant film formation, load carrying capacity, oil transport and wear. These are often, but not always, ignored in analyses of largely academic nature.

Figure 8 shows the variation of the predicted minimum film thickness for a new ring conforming to an ideal right circular cylindrical liner, as well as those predicted for an oval liner (i.e. $n=2$ ) with Hill and Newman [3] and Tomanik [23] conformation bounds. It can be seen that due to predicted full conformance, the results for the case of Hill and Newman approach follows that of the ideal circular cylindrical bore, even at light sealing loads in other engine strokes than the power stroke. In practice such conditions are not encountered as they would contravene oil transport through the ring-pack. Thus, in the remaining analyses, Tomanik [23] bounds are used. 
Proceedings of the Institution of Mechanical Engineers, Part J: Journal of Engineering Tribology, 2012, Vol. 226, No. 4, pp. 284-305

(Accepted Version)

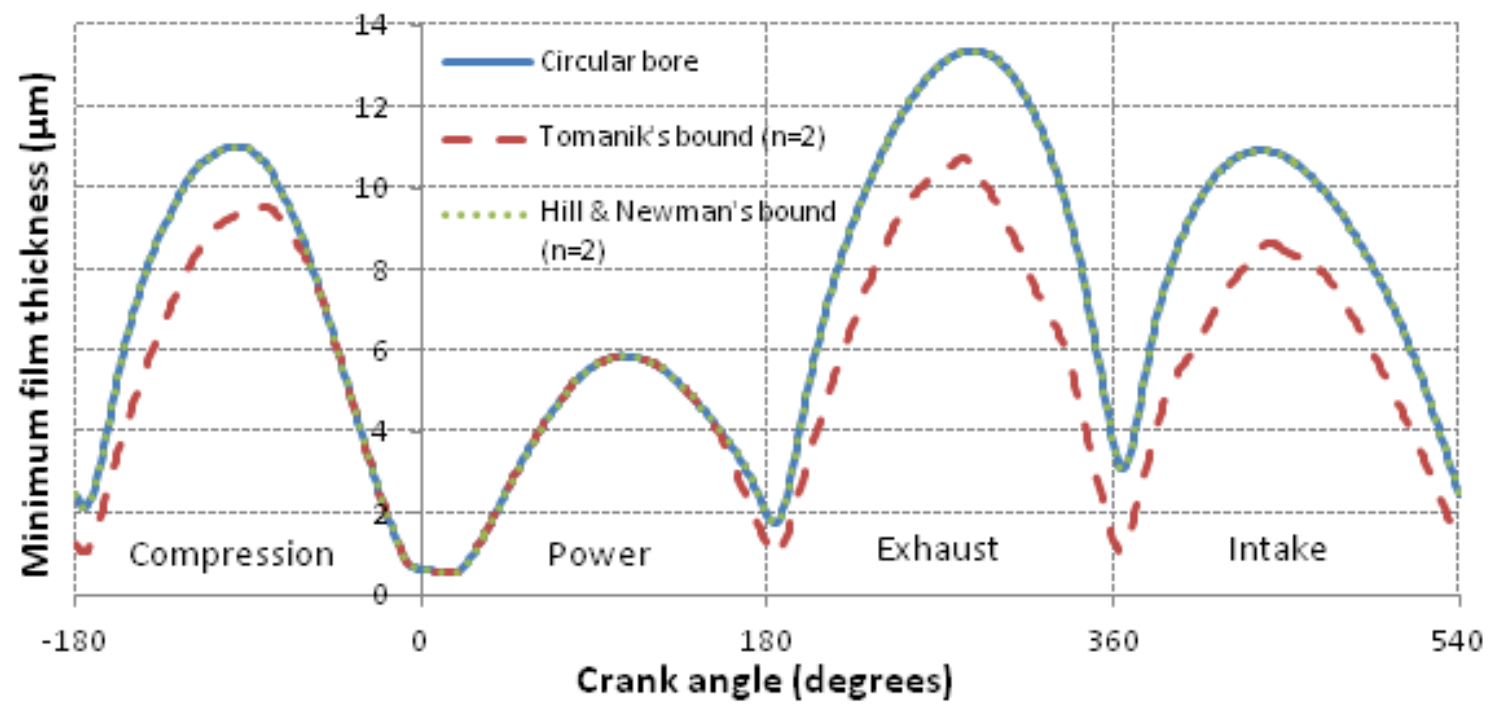

Figure 8: Transient minimum film thickness for a new ring-bore conjunction

Figure 8 also shows that for part of the compression and all of the power stroke, high combustion pressures tend to conform the ring to the bore, resulting in quite thin lubricant films, particularly at the top dead centre $\left(\varphi=0^{\circ}\right)$. Of course, as shown in Figure 6 the bore cross-section is multi-lobed. Therefore, the minimum film thickness in the ring-bore conjunction is affected most pertinently by the higher bore orders.

A series of axial pressure profiles along the ring face-width is shown in Figure 9 in the transition from the compression to power stroke, extending to maximum combustion pressure at $21^{\circ}$ crank-angle position past the TDC (at $\varphi=0^{\circ}$ ). They are self-explanatory, showing inlet pressure being the chamber pressure in the compression stroke and the crank-case pressure in the power stroke. 
Proceedings of the Institution of Mechanical Engineers, Part J: Journal of Engineering Tribology, 2012, Vol. 226, No. 4, pp. 284-305

(Accepted Version)
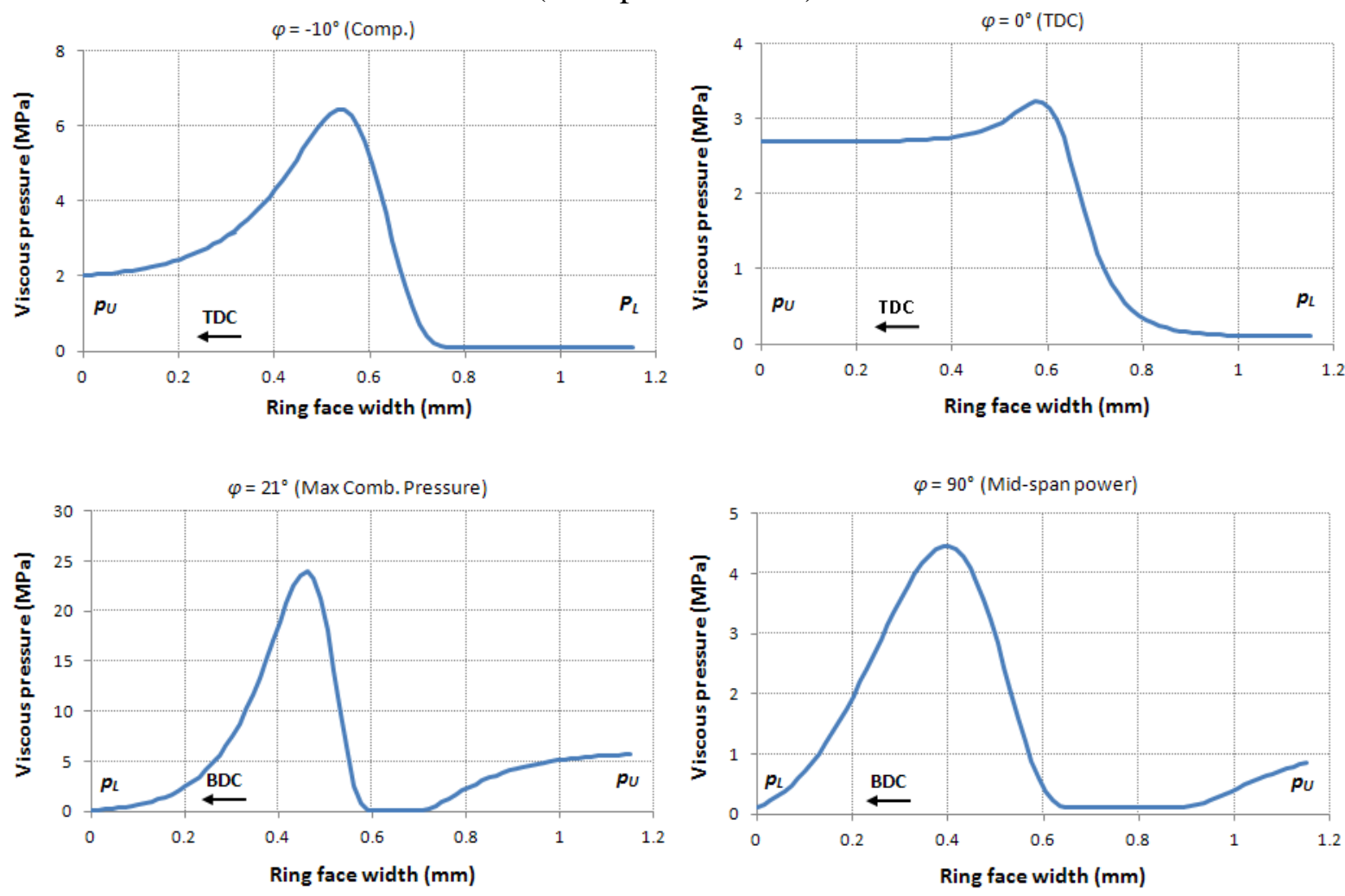

Figure 9: Pressure distribution in the ring/liner conjunction at various crank-angles (cross-section facing the end gap)

Figure 10 shows the minimum film thickness for the new and worn rings at different clearance scales, determined by the various bore orders $n$. It can be observed that the minimum film thickness remains almost unchanged with increasing out-of-roundness in the areas of high combustion pressure; as the ring tends to conform closer to the bore surface. However, elsewhere higher bore orders constitute increased bore surface waviness which results in a reduction in the minimum film thickness. Whilst higher number of lobes creates regions of higher pressure, the magnitudes of these are insufficient to cause any localised surface deformation. In most of the engine cycle, the prevalent regime of lubrication is in fact hydrodynamic with relatively thick films. Larger film thickness has repercussions for oil transport and viscous friction, but to a much lesser degree in the case of the latter than the 
Proceedings of the Institution of Mechanical Engineers, Part J: Journal of Engineering Tribology, 2012, Vol. 226, No. 4, pp. 284-305

(Accepted Version)

mixed regime of lubrication with thin films encountered at piston reversals, particular at the TDC and in the power stroke.

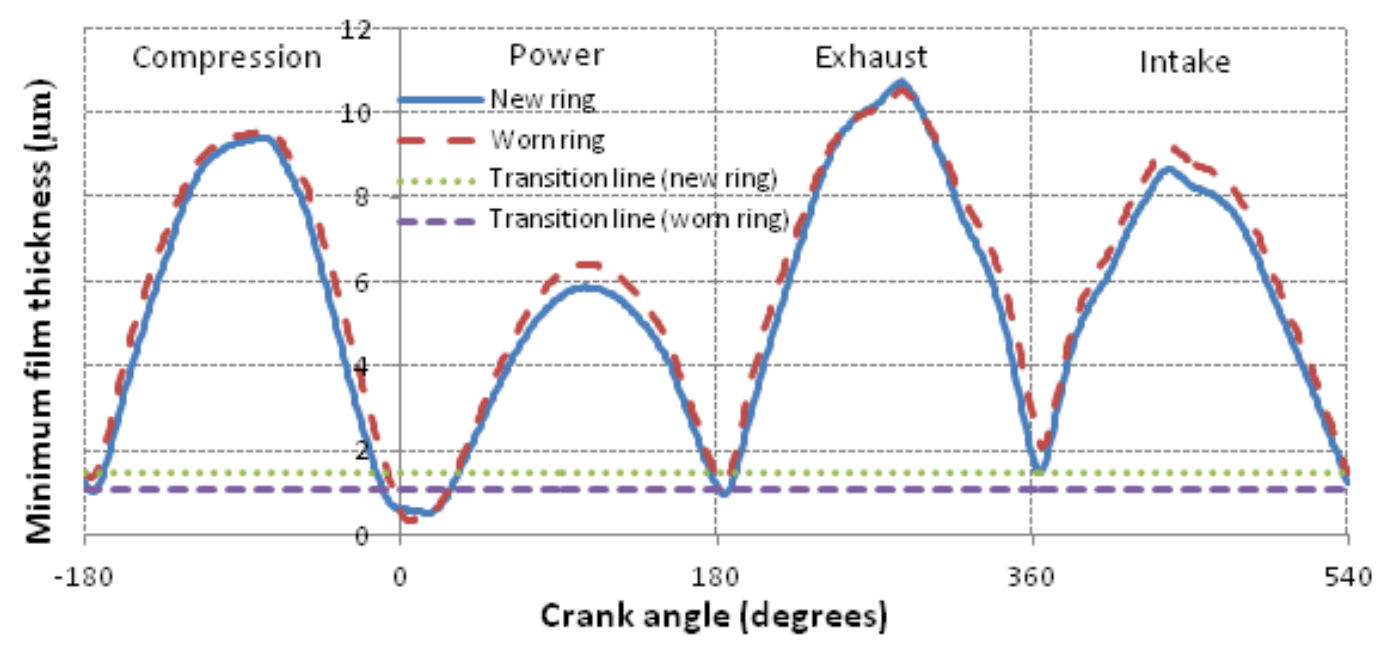

(a)- An oval bore, $n=2$

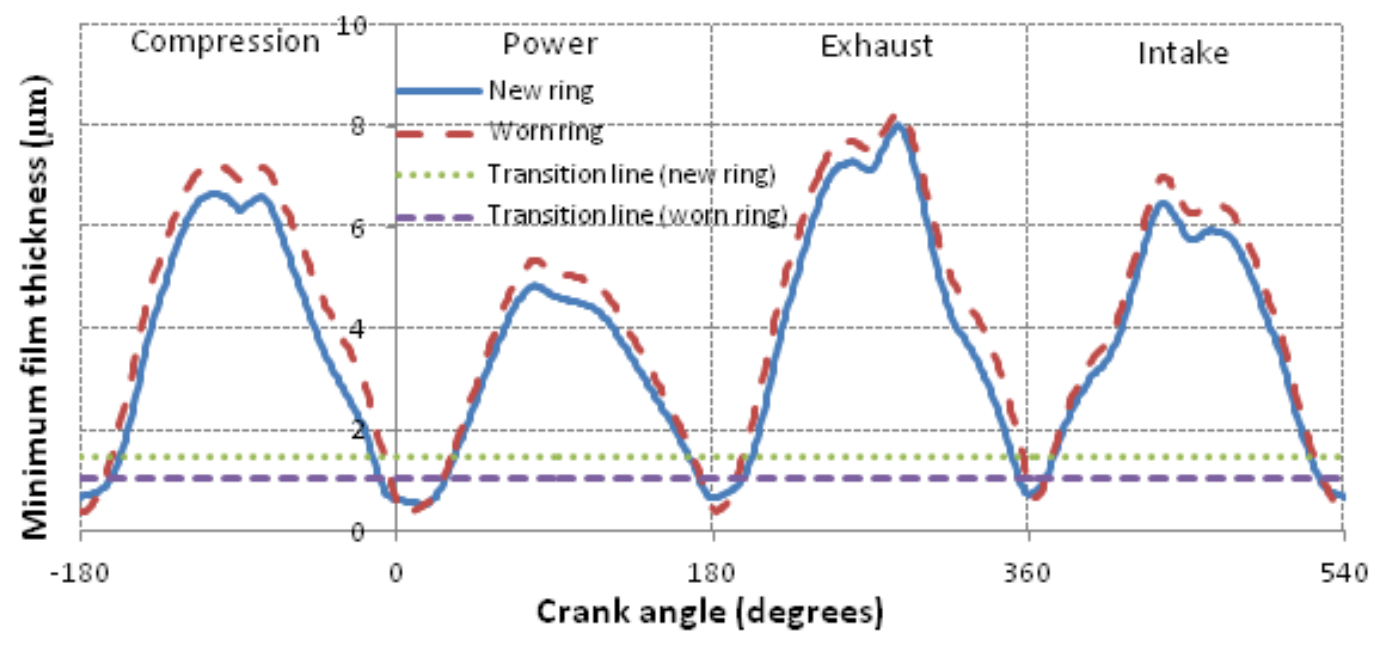

(b)- Distorted out of round bore of $n=3$ 
Proceedings of the Institution of Mechanical Engineers, Part J: Journal of Engineering Tribology, 2012, Vol. 226, No. 4, pp. 284-305

(Accepted Version)

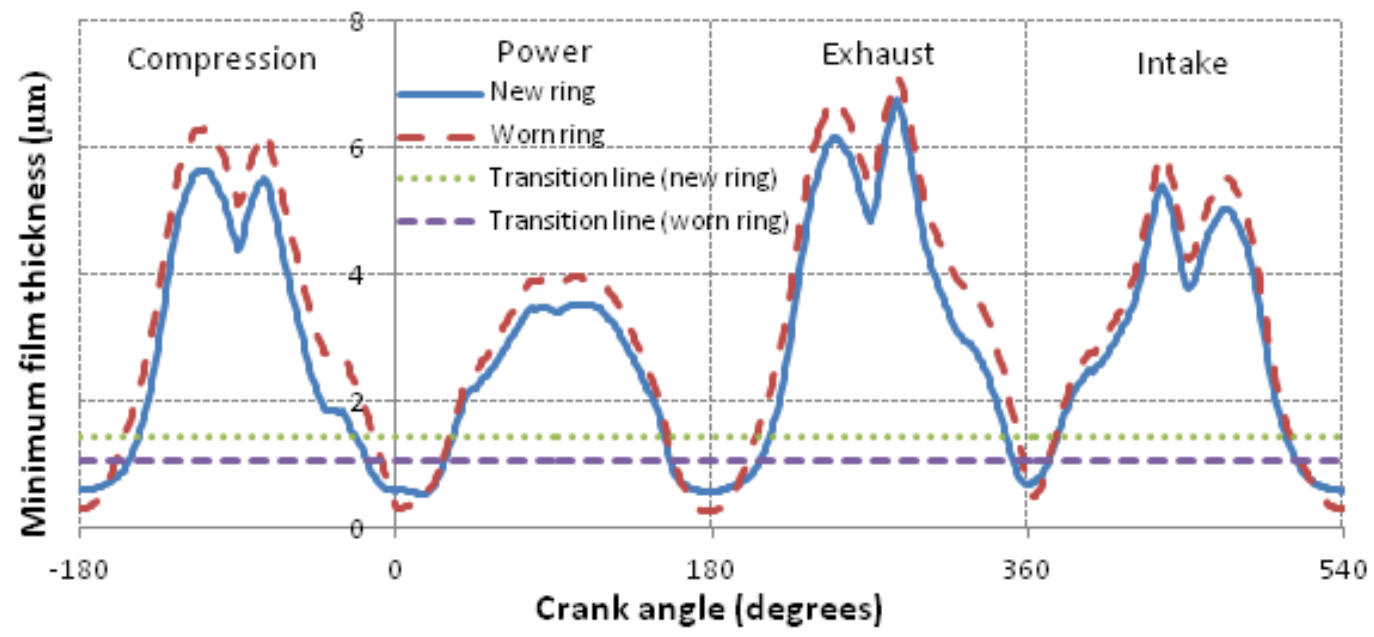

(c)- Distorted out of round bore of $n=4$

Figure 10: Transient minimum oil film thickness for new and worn rings

Figure 10 also shows the effect of ring wear upon conjunctional film formation. The measured worn ring used in the analysis is one which has undergone periods of initial and gradual wear, and considered to have reached its eventual embedded state (run-in). The results show that a worn ring promotes a marginally thicker film than a new one. This finding is in line with generally regarded intuition. However, at instances of closest ring-bore separation the minimum film is hardly affected. Nevertheless, lower boundary friction may ensue because of changes in surface roughness profile as indicated by representative topographical parameters (see Table 3). The transition lines from hydrodynamics to mixed regime of lubrication for the new and worn rings are also shown in Figure 10, based on the oil film parameter, $\lambda=3$. Note that this transition occurs at thicker films for a new ring as it would be expected. This is because of rougher surface topography of the new ring.

Figure 11 shows contributions to total friction for a new ring-to-an oval bore conjunction, arising from viscous shear of the lubricant film as well as boundary interactions as the result 
Proceedings of the Institution of Mechanical Engineers, Part J: Journal of Engineering Tribology, 2012, Vol. 226, No. 4, pp. 284-305

(Accepted Version)

of asperity friction. It can be seen that asperity friction dominates the total friction at and in the vicinity of the top dead centre during the power stroke. Note that the corresponding film thickness is quite thin in Figure 10(a). Therefore, the prevailing regime of lubrication is mixed. The inset to the figure shows the dominance of boundary friction in the aforementioned region.

With exacerbated bore waviness (increasing $n$ ), the contribution due to boundary friction extends to reversals in other engine strokes as it can be observed in Figure 11(b).

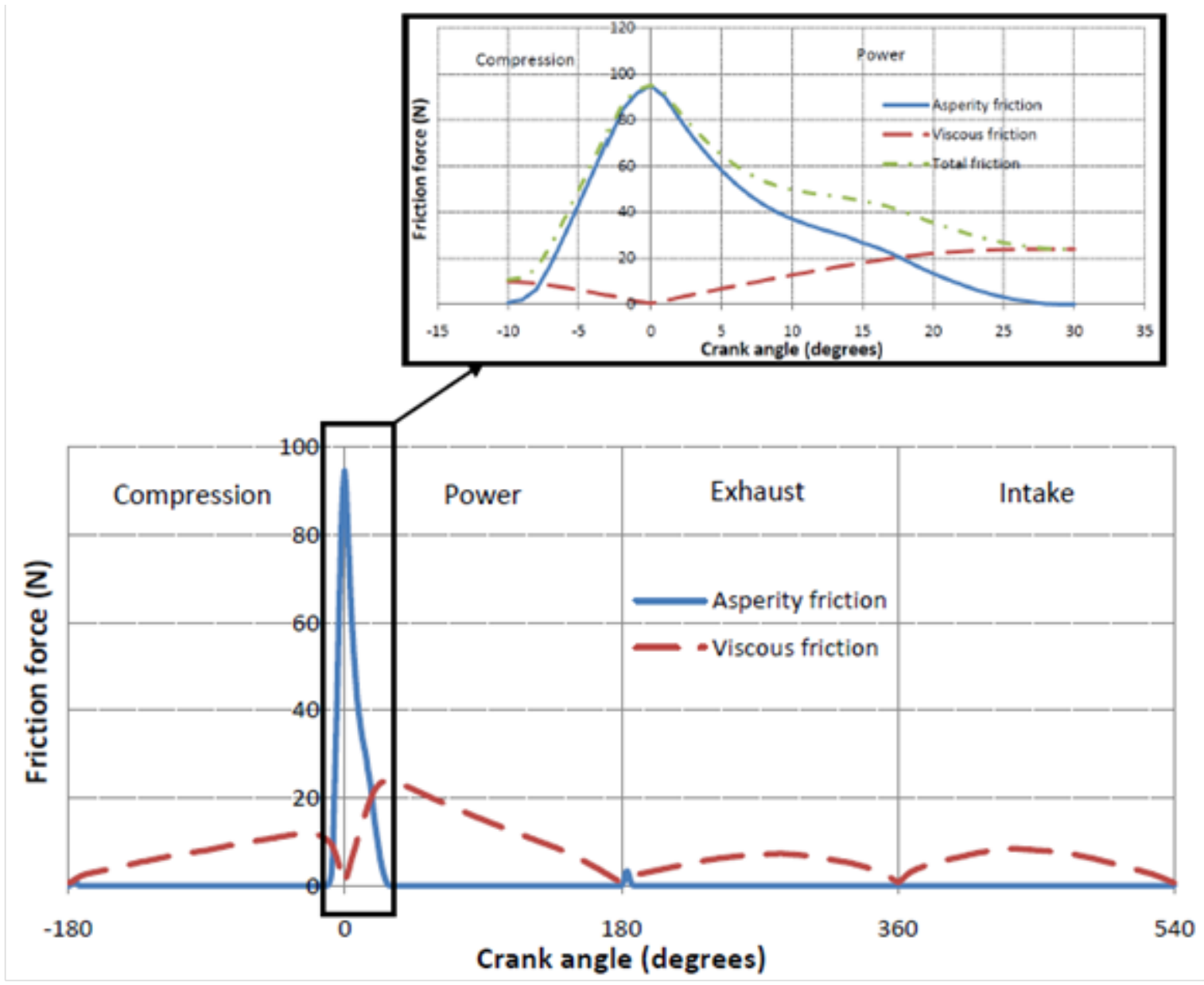

(a)- For $n=2$ 
Proceedings of the Institution of Mechanical Engineers, Part J: Journal of Engineering Tribology, 2012, Vol. 226, No. 4, pp. 284-305

(Accepted Version)

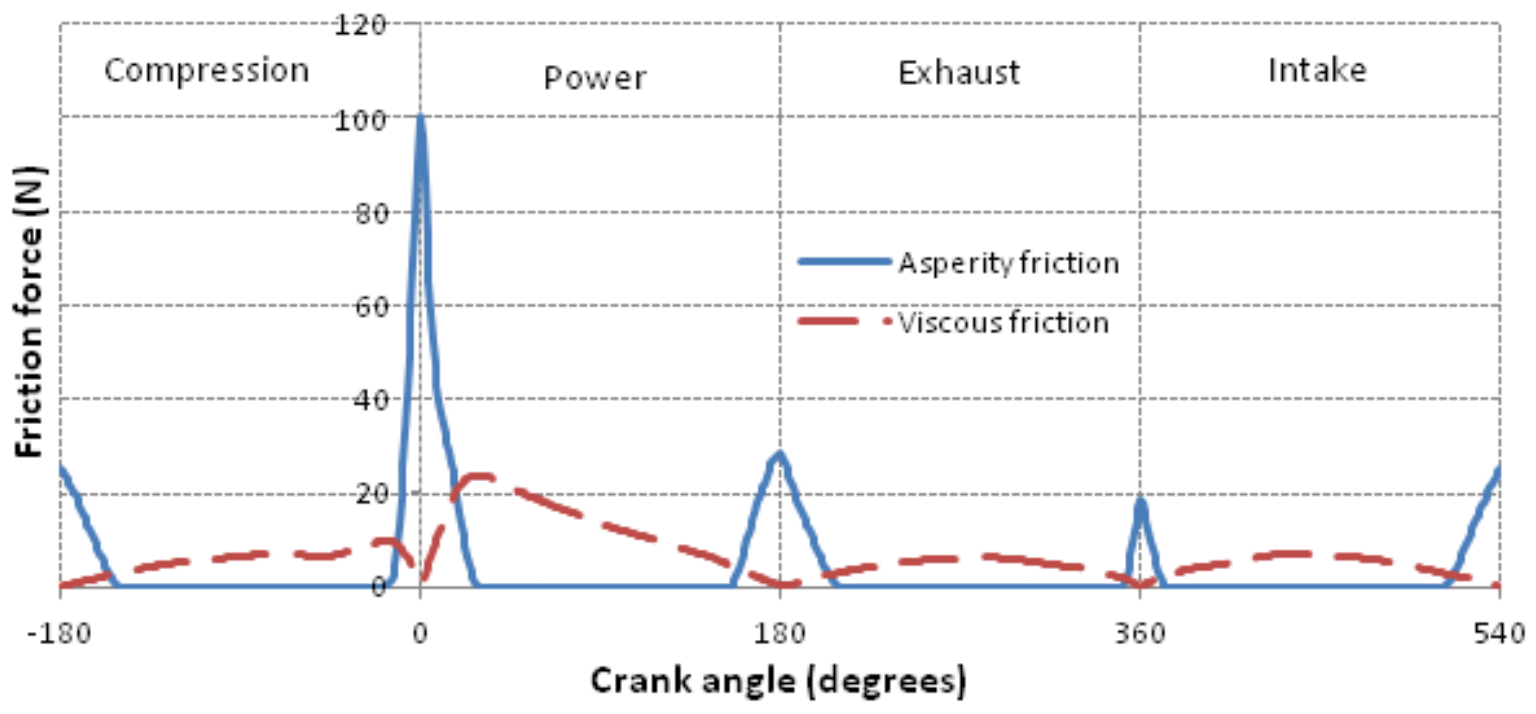

(b)- For $n=4$

Figure 11: Mechanisms of ring-bore friction and their contributions in various engine strokes for the new ring

The effect of ring wear on friction is shown in Figure 12 for various bore orders. Wear affects both the geometry of the conjunction (macro-scale, Figure 2) as well as the topography of the ring surface (micro-scale, Table 3). Figure 12 shows the trend in the average frictional contributions for new and worn embedded (run-in) rings for different bore orders. Clearly, the new ring shows higher boundary friction, as this would be the underlying reason for its wear. Boundary friction increases significantly with more wavy bores (higher values of $n$ ). Note that the embedded worn ring is smoother than the new one. The worn ring geometry also encourages a slightly better wedge effect, thus marginally improves the film thickness and thus lowers viscous friction. As the bore order increases, the waviness of the bore surface pronounces the ring-bore gap, forming a thicker film and a correspondingly lower viscous friction. Thus, run-in worn rings improve friction. This is in line with experience of the multistage wear from initial rapid to gradual wear, resulting ultimately in a run-in (embedded) 
Proceedings of the Institution of Mechanical Engineers, Part J: Journal of Engineering Tribology, 2012, Vol. 226, No. 4, pp. 284-305

(Accepted Version)

ring. Gore et al [44] show this process for a ring of similarly high performance engine, where the wear rate to reach run-in status is quite rapid.

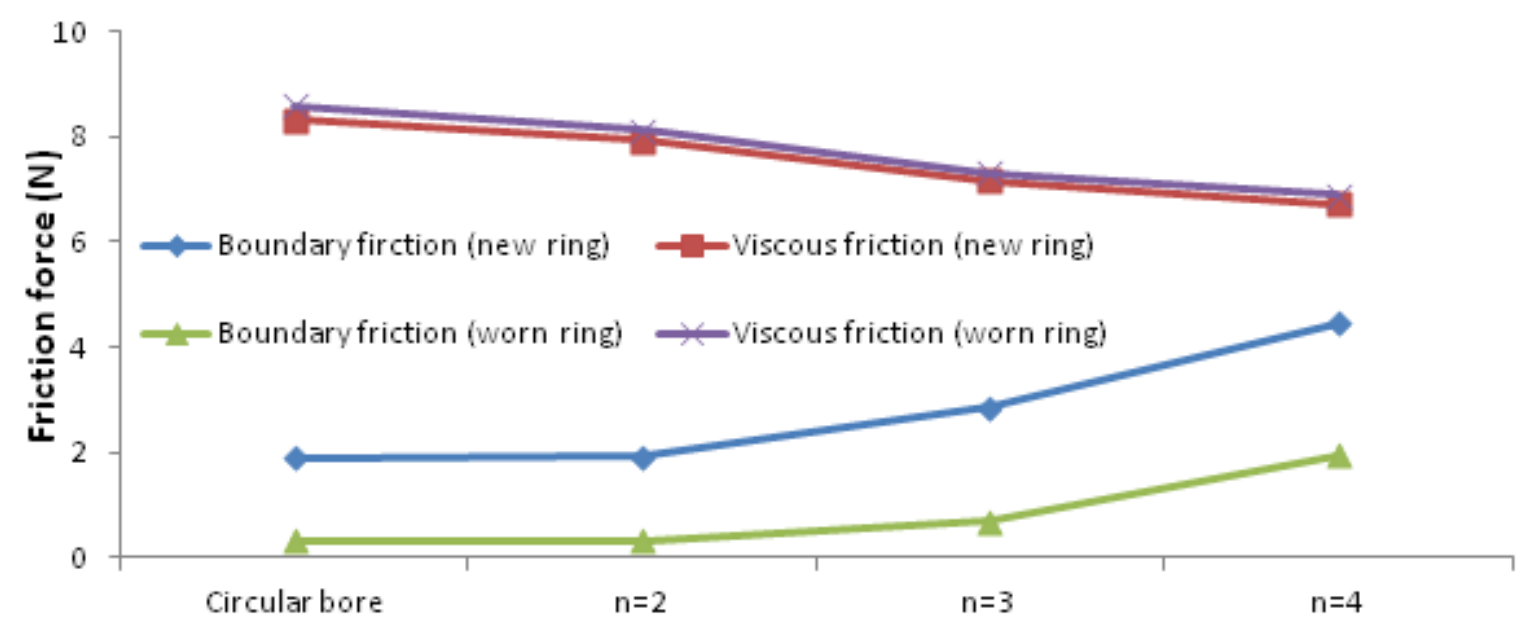

Figure 12: Contribution of mechanisms of friction with different combinations of bore out-of-roundness and ring topographical state

In practice, the uneven wear of the ring and the multi-lobed nature of the bore results in preferential wear of the liner. This also affects the film thickness profile in essentially circumferentially distributed fashion. Larger clearance gaps are then formed in between these mini-conjunctions. A coherent film of lubricant may not be formed in such gaps, although the analysis here assumes a fully flooded inlet and a coherent film of lubricant in emerging gaps. In practice, gaps exceeding certain limiting separation cannot support an oil film due to insufficient generated pressures. When the pressure falls below the lubricant vaporisation pressure a coherent film of lubricant is not formed. Instead, two phase flow of lubricant vapour streams in an incoherent lubricant film would be expected [26].

With the aforementioned assumptions of a fully flooded inlet and a coherent lubricant film in a gap of any size, Figure 13 shows the volumetric flow through a new ring for different bore 
Proceedings of the Institution of Mechanical Engineers, Part J: Journal of Engineering Tribology, 2012, Vol. 226, No. 4, pp. 284-305

(Accepted Version)

out-of-roundness. As higher bore order is considered, corresponding to ever decreasing scale of analysis, a larger volumetric flow rate is predicted, using:

$\vec{q}=-\frac{1}{12} \frac{h^{3}}{\eta} \vec{\nabla} p+\frac{h}{2} \vec{V}$

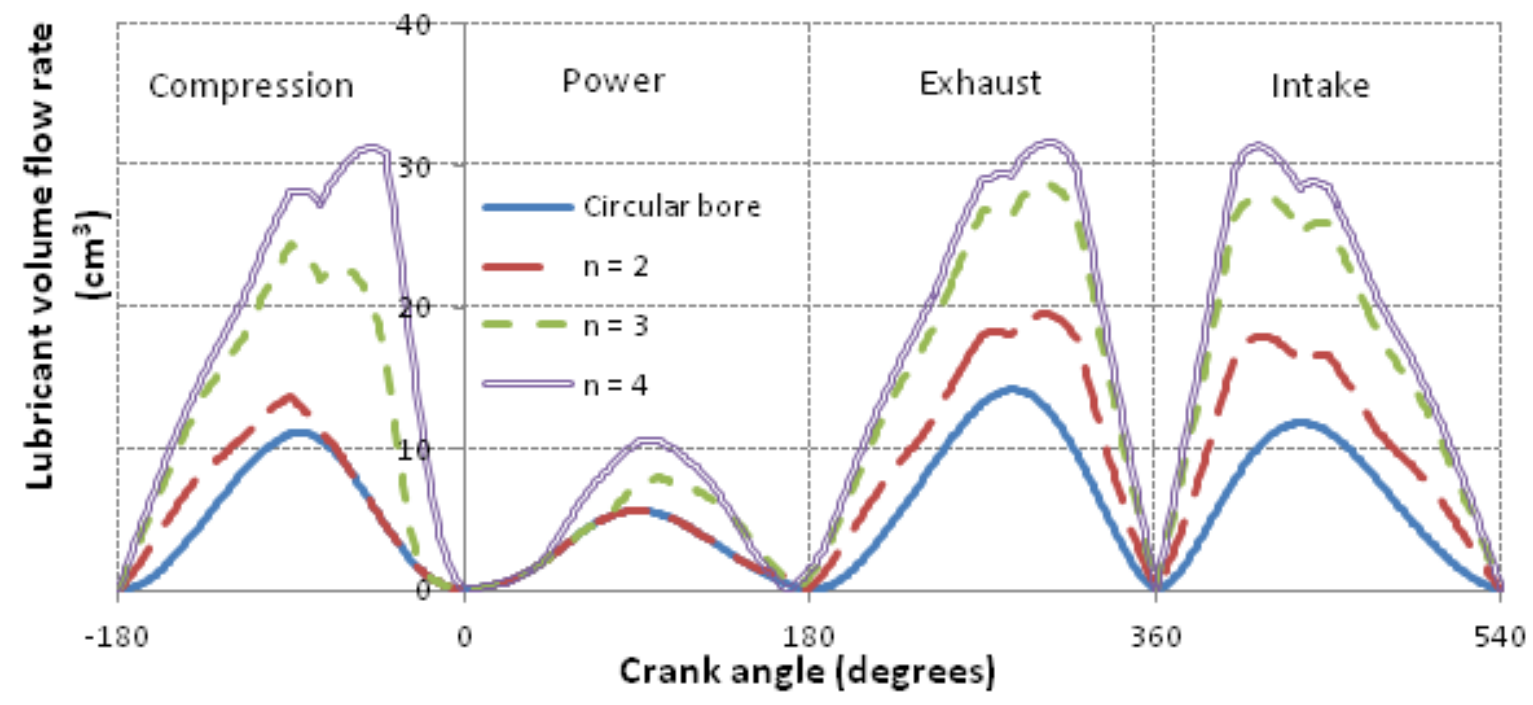

Figure 13: Lubricant flow characteristics in ring-bore conjunction with different bore orders

As the ring-liner separation becomes large in diminutive detail by higher bore order, the volumetric flow increases accordingly. This shows that inclusion of bore waviness is required in order to arrive at more realistic analyses. There is of course a limit to this, as an increasing value of $n$ culminates with surface roughness features. At such a level, with an assumed roughness peak topography, bulk lubricant properties give way to its physical chemistry and often the molecular properties of lubricant additives determine the tribological conditions. They promote formation of low shear strength surface films with flow characteristics quite different to hydrodynamic flow [45-46].

The predicted flow rate, when carried out for the entire ring pack, comprising a number of rings with suitably staggered end-gaps and the inclusion of a cavitation region will provide a 
Proceedings of the Institution of Mechanical Engineers, Part J: Journal of Engineering Tribology, 2012, Vol. 226, No. 4, pp. 284-305

(Accepted Version)

measure of blow-by gasses. This is one of the aims of future work of the current research. It would feed into the industrial imperative of reduced emissions and particularly dilution of the lubricant by fuel.

The other over-riding industrial objective is to predict frictional losses from all the conjunctions of the piston-cylinder system. The current analysis enables this objective for the case of the top compression ring. Frictional power loss during a cycle can be obtained for the compression ring in either new or run-in state within an out-of-round bore of any bore order. Figure 14 shows the power losses for a new ring in different out-of-round bores. It is clear that the greatest share of losses occur in the power stroke and in the region of high combustion pressures. It is, however, more useful to represent these losses in terms of percentage of input fuel energy consumed. This loss of energy occurs through an entire engine cycle. For the 4-stroke engine under investigation here, the total loss of the compression ring in a typical engine cylinder is obtained as the area beneath any given continuous curve in Figure 14:

$$
\begin{aligned}
& E_{\text {loss }}=\int_{0}^{t_{c y c l e}} P d t=\sum_{i=1}^{720}\left(P_{i} \cdot \Delta t\right)=\Delta t \sum_{i=1}^{720}\left(P_{i}\right)=\left(\frac{t_{c y c l e}}{720}\right) \sum_{i=1}^{720}\left(P_{i}\right)=t_{c y c l e} \cdot \frac{\sum_{i=1}^{720}\left(P_{i}\right)}{720}= \\
& t_{c y c l e} \cdot P_{\text {avg }}
\end{aligned}
$$

where, $t_{c y c l e}$ is the engine cycle time as a function of engine speed, $t_{c y c l e}=\varphi_{l} \omega, \varphi=4 \pi$.

The input fuel energy is easily obtained, when the mass flow rate through the ring is obtained using Figure 13. The procedure is highlighted in Appendix B. 
Proceedings of the Institution of Mechanical Engineers, Part J: Journal of Engineering Tribology, 2012, Vol. 226, No. 4, pp. 284-305

(Accepted Version)

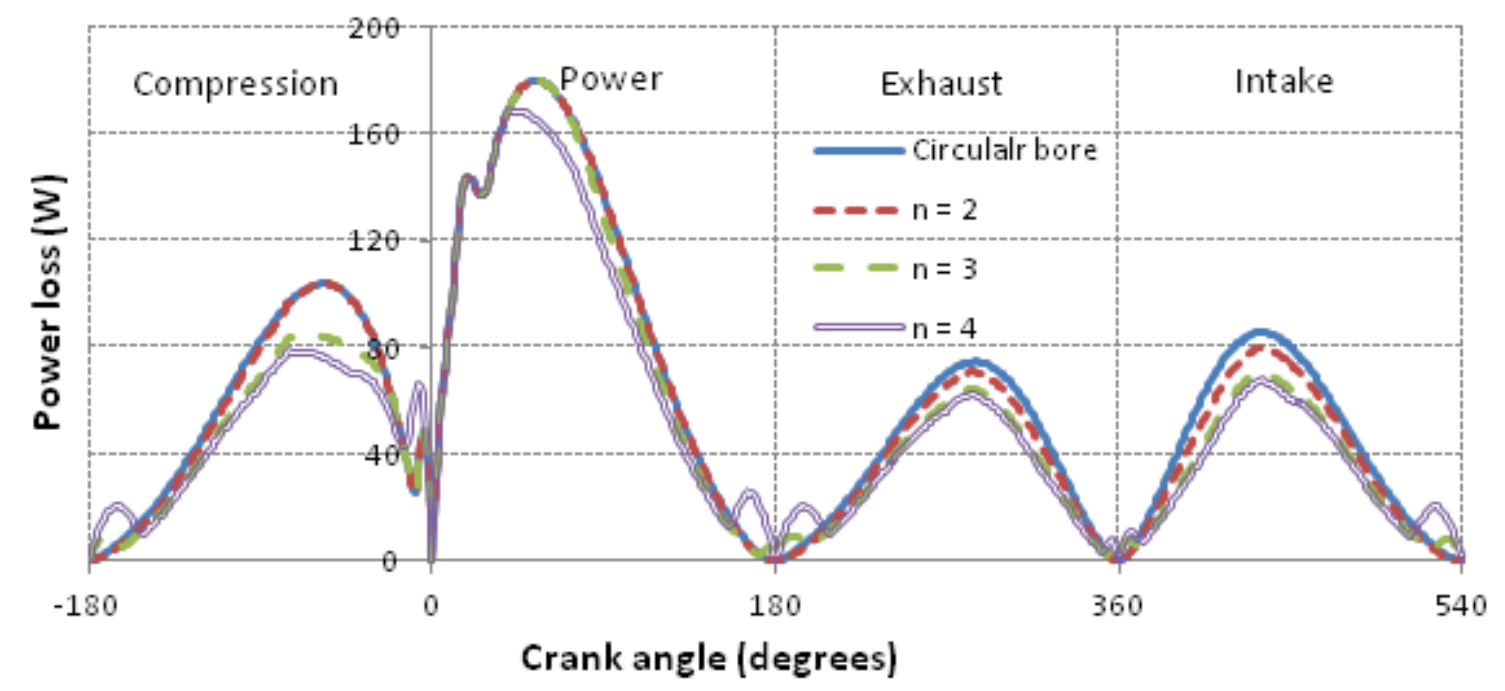

Figure 14: Frictional power loss of a new ring in different bores

Figure 15 shows the percentage of fuel energy lost by a new or run-in worn ring for an oval or a bore of order of 3. At lower engine speeds, friction is dominated by asperity interactions at dead centre reversals. Thus, the worn ring, having a smoothened surface, consumes a lower portion of fuel energy than a new ring. This is because of reduced boundary interactions. As the engine speed is increased hydrodynamic contribution prevails and thicker films are formed. Thicker films also constitute reduced piezo-viscous action (reduced lubricant viscosity), thus increased shear stress and viscous friction. Hence, the worn ring, having a larger film thickness shows an increase in fuel consumption. In practice, in sufficiently large gaps, lubricant vaporisation may take place and in fact reduce the viscous friction. With the assumed fully flooded condition and no cavitation zone, as in the current study, the true effect of viscous friction cannot be ascertained. Therefore, the main difference in fuel energy use between a new and a worn ring is attributable to the boundary friction as shown in Figure 12. 
Proceedings of the Institution of Mechanical Engineers, Part J: Journal of Engineering Tribology, 2012, Vol. 226, No. 4, pp. 284-305

(Accepted Version)

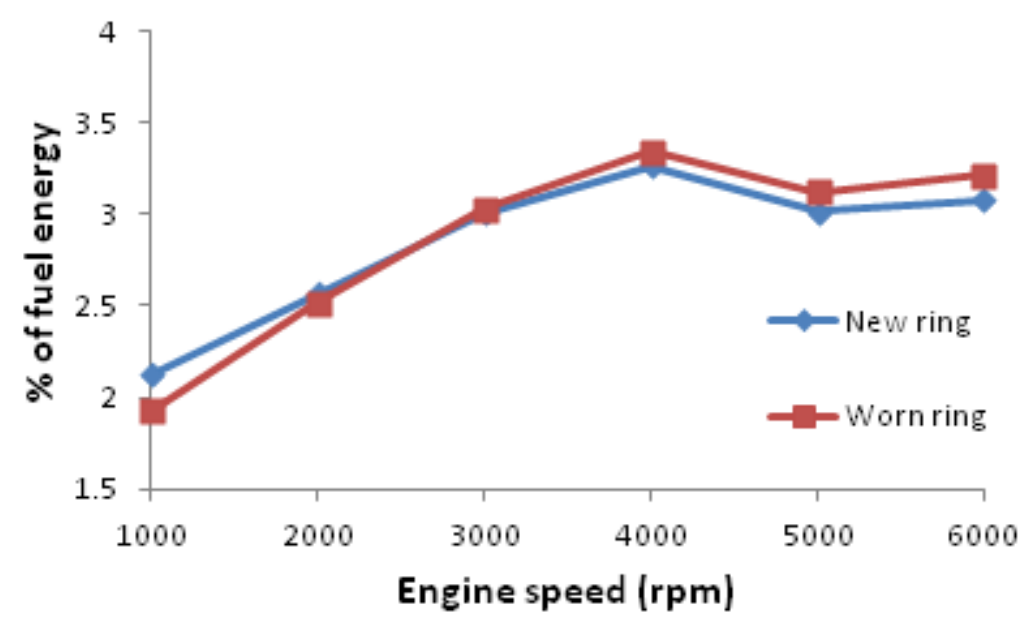

(a)- For $n=2$ (an oval bore)

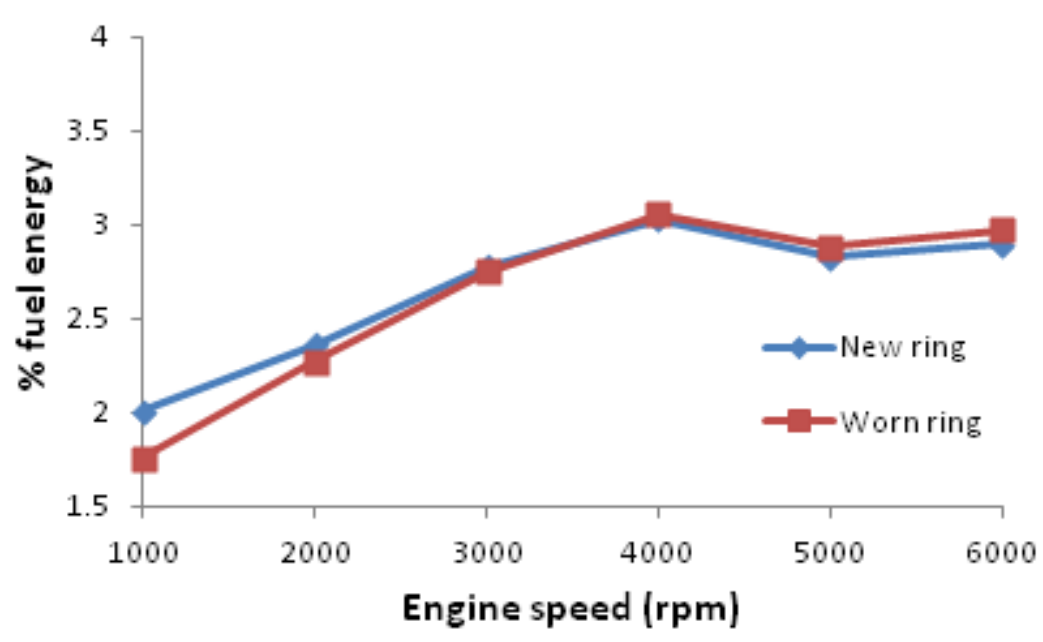

(b)- For $n=3$

Figure 15: Fuel energy consumed by the compression ring

\section{Conclusions and Future Work}

The analysis shows that the actual bore is not only out-of-round, but also axially asymmetric.

This means that the bore may be considered as multi-lobed, which may be represented as a hierarchical wavy surface. Thus, an incomplete nominally circular ring in situ within such a bore would conform to a varying degree to its surface as a problem of physical scale, which is 
Proceedings of the Institution of Mechanical Engineers, Part J: Journal of Engineering Tribology, 2012, Vol. 226, No. 4, pp. 284-305

(Accepted Version)

also affected by ring elasticity, ring tension and the applied gas pressure. The degree of conformity is subject to transience because of the bore asymmetry, both axially and radially. Hence, conformability of ring-bore contact requires two dimensional analysis and yields the instantaneous ring-bore conjunction. Current work shows the complexity of bore geometry as well as ring face-width profile. By including such salient features the current work extends those reported in literature in order to arrive closer to real conditions. As a result, the predictions show a transient regime of lubrication which affects the underlying mechanisms of friction, which determine the cyclic power losses and proportion of fuel energy consumed by the ring. Additionally, lubricant flow through the ring can also be estimated. The predictions made are in line with findings of other research workers and in-field experience.

The current analysis makes certain assumptions, such as a flooded inlet to the conjunction and absence of a cavitation zone, both of which affect viscous friction. Furthermore, isothermal conditions are assumed. This would over-estimate lubricant viscosity, thus the load carrying capacity of multi-lobed conjunctions, friction and lubricant flow. A thermohydrodynamic analysis should be carried out, coupled with conduction of heat away from bounding surfaces. This constitutes simultaneous solution of the above method with energy equation at any instant of time. It is anticipated that such a solution would yield thinner lubricant films, thus higher viscous shear stress and friction.

With the boundary friction approach used here, the properties of substrate material, being steel in this instance were used. However, as noted previously, the ring is usually furnished with a hard wear resistant coating, whose asperity level interactions deviate from the substrate material. These should also be measured and included in future analyses.

Nevertheless, new and run-in (embedded) ring profiles and topography were included in the analyses. These have shown the effect of wear upon tribological performance of the 
Proceedings of the Institution of Mechanical Engineers, Part J: Journal of Engineering Tribology, 2012, Vol. 226, No. 4, pp. 284-305

(Accepted Version)

conjunction. It is shown that boundary friction and the ensuing account for the main part of any reduction in power loss from a new to a run-in ring.

\section{Acknowledgements}

The authors wish to express their gratitude to Engineering and Physical Sciences Research Council (EPSRC) for the funding extended to the Encyclopaedic Program Grant (www.Encyclopaedic.org), under which this research is carried out in collaboration with a consortium of industry and academic institutions. In particular, the authors acknowledge the financial and technical support of Aston Martin Lagonda.

\section{References}

(1) Taylor, C.M. (1998) ‘Automobile engine tribology - design considerations for efficiency and durability', Wear, 221, pp. 1-8

(2) Tung, S.C. and McMillan, M.L. (2004) 'Automotive tribology: overview of current advances and challenges for the future', Trib. Int., 37, pp. 517-536

(3) Hill, S.H. and Newman, B.A. (1985) 'Piston ring designs for reduced friction', SAE Paper No. 841222

(4) Priest M. and Taylor C.M. (2000) 'Automobile engine tribology - approaching the surface', Wear, 241, pp. 193-203

(5) Furuhama, S. (1959) 'A Dynamic theory of piston ring lubrication, 1st Report calculation', Bulletin of JSME, 2, p. 423 
Proceedings of the Institution of Mechanical Engineers, Part J: Journal of Engineering Tribology, 2012, Vol. 226, No. 4, pp. 284-305

(Accepted Version)

(6) Dowson, D., Ruddy, B.L. and Economou, P.L. (1983) 'The elastohydrodynamic lubrication of piston rings', Proc. Roy. Soc. London, Series A, Mathematical and Physical Sciences, 386 (1791), pp. 409-430

(7) Hwu, C.-J. and Weng, C.-I. (1991) 'Elastohydrodynamic lubrication of piston rings', Wear, 151, pp.203-215

(8) Jeng, Y.-R. (1992) 'Theoretical analysis of piston-ring lubrication, Part I - fully flooded lubrication’, STLE Trib. Trans., 35(4), pp. 696-706

(9) Jeng, Y.-R. (1992) 'Theoretical analysis of piston-ring lubrication, Part II - starved lubrication and its application to a complete ring pack', STLE Trib. Trans., 35(4), pp. 707714

(10) Patir, N. and Cheng, H.S. (1978) 'An average flow model for determining effects of three-dimensional roughness on partial hydrodynamic lubrication', Trans. ASME, Series F: J. Lubn. Tech., 100, pp. 12-17

(11) Sui, P.C. and Ariga, S. (1993) 'Piston ring pack friction and lubrication analysis of an automotive engine using a mixed lubrication model', SAE Paper No. 931937

(12) Akalin, O. and Newaz, G.M. (2001) 'Piston ring-cylinder bore friction modeling in mixed lubrication regime, Part I - analytical results', Trans. ASME, Series F: J. Trib., 123, pp. $211-218$

(13) Akalin, O. and Newaz, G.M. (2001) 'Piston ring-cylinder bore friction modeling in mixed lubrication regime, Part II - Correlation With Bench Test Data', Trans. ASME, Series F: J. Trib., 123, pp. 219-223 
Proceedings of the Institution of Mechanical Engineers, Part J: Journal of Engineering Tribology, 2012, Vol. 226, No. 4, pp. 284-305

(Accepted Version)

(14) Furuhama, S. and Sasaki, S. (1983) 'New device for the measurement of piston frictional forces in small engines', SAE Paper No. 831284

(15) Ma, M.-T., Sherrington, I. and Smith, E.H. (1997) 'Analysis of lubrication and friction for a complete piston-ring pack with an improved oil availability model - Part 1: circumferentially uniform film', Proc. IMechE, Part J: J. Engng. Trib., 211, pp. 1-15

(16) Mishra, P.C., Balakrishnan, S. and Rahnejat, H. (2008) 'Tribology of compression ringto-cylinder contact at reversal’, Proc. IMechE, Part J: J. Engng. Trib., 222, pp. 815-826

(17) Mishra, P.C., Rahnejat, H. and King, P.D. (2009) 'Tribology of the ring-bore conjunction subject to a mixed regime of lubrication', Proc. IMechE, Part C: J. Mech. Engng. Sci., 223(4), pp. 987-998

(18) Hu, Y., Cheng, H.S., Arai, T., Kobayashi, Y. and Aoyama, S. (1994) 'Numerical simulation of piston ring in mixed lubrication - A non-axisymmetrical analysis', Trans ASME, J. Trib., 116, pp. 470-478

(19) Bolander, N.W., Steenwyk, B.D., Sadeghi, F. and Gerber, G.R. (2005) 'Lubrication regime transitions at the piston ring-cylinder liner interface’, Proc. IMechE. Part J: J. Engng. Trib., 219, pp. 19-31

(20) D’Agostino, V. and Senatore, A., 'Fundamentals of lubrication and friction of piston ring contact', in Rahnejat (Ed.): Tribology and Dynamics of Engine and Powertrain Fundamentals, applications and future trends, Woodhead Publishing Ltd., 2010, Cambridge, UK.

(21) Han, D.-C. and Lee, J.-S. (1998) 'Analysis of the piston ring lubrication with a new boundary condition', Trib. Int., 31(12), pp. 753-760 
Proceedings of the Institution of Mechanical Engineers, Part J: Journal of Engineering Tribology, 2012, Vol. 226, No. 4, pp. 284-305

(Accepted Version)

(22) Piao, Y. and Gulwadi, S. (2003) 'Numerical investigation of the effects of axial cylinder bore profiles on piston ring radial dynamics', Trans. ASME, J. Engng. for Gas Turbines and Power, 125, pp. 1081-1089

(23) Tomanik, E. (1996) 'Piston ring conformability in a distorted bore', SAE Paper No. 960356

(24) Pinkus, O. and Sternlicht, B. (1961) Theory of hydrodynamic lubrication, McGraw-Hill Inc., USA

(25) Rahnejat, H. (1998) Multi-body dynamics: vehicles, machines and mechanisms, Professional Engineering Publishing (IMechE, Bury St Edmunds, UK) and SAE (Warrandale, PA, USA), Joint Publishers.

(26) Chong, W.W.F., Teodorescu, M. and Vaughan, N. (2010), 'Cavitation induced starvation for piston-ring/liner tribological conjunction', Trib. Int., 44(4), pp. 483-497

(27) Roelands, C.J.A. (1966) Correlation aspects of the viscosity-temperature-pressure relationships of lubricating oils, Druk VRB Kleine der A3-4 Groningen

(28) Dowson, D. and Higginson, G.R. (1959) 'A numerical solution to the elastohydrodynamic problem', J. Mech. Eng. Sci., 10, Part1, pp. 6-15

(29) Gohar, R. and Rahnejat, H. (2008) Fundamentals of Tribology, Imperial College Press, London, UK

(30) Arcoumanis, C., Duszynski, M., Flora, H. and Ostovar, P. (1995) ‘Development of a piston-ring lubrication test-rig and investigation of boundary conditions for modelling lubricant film properties', SAE Paper No. 952468 
Proceedings of the Institution of Mechanical Engineers, Part J: Journal of Engineering Tribology, 2012, Vol. 226, No. 4, pp. 284-305

(Accepted Version)

(31) Mufti, R.A., Priest, M. and Chittenden, R.J. (2008) 'Analysis of piston assembly friction using the indicated mean effective pressure experimental method to validate mathematical models', Proc. IMechE, Part D: J. Automobile Engng., 222(8), pp. 1441-1457

(32) Abe, S. and Suzuki, M. (1995) 'Analysis of cylinder bore distortion during engine operation', SAE Paper No. 950541

(33) Bardzimashvili, T., Kelly, J.F., Romelashvili, H., Sledd, W.T. and Geist, B. (2004) ‘A multiple order conformability model for uniform cross-section piston rings', SAE Paper No. $05 P 734$.

(34) Dunaevsky, V.V. (1990) 'Analysis of distortions of cylinders and conformability of piston rings', STLE Trib. Trans., 3 (1), pp. 33-40

(35) Loenne, K and Ziemba, R. (1989) 'The Goetze cylinder distortion measurement system and the possibilities of reducing cylinder distortions', SAE Paper No. 880142

(36) Jalali-Vahid, D., Rahnejat, H., Gohar, R. and Jin, Z.M. (1998) 'Comparison between experiments and numerical solutions for isothermal elastohydrodynamic point contacts', $J$. Phys., D: Appl. Phys., 31, 2725

(37) Balakrishnan, S. and Rahnejat, H. (2005) 'Isothermal transient analysis of piston skirtto-cylinder wall contacts under combined axial, lateral and tilting motion', J. Phys., D: Appl. Phys., 38, 787

(38) Bin Chik, A. and Fessler, H. (1966) 'Radial pressure exerted by piston rings', J. Strain Anal., I ( 2), pp. 165-171 
Proceedings of the Institution of Mechanical Engineers, Part J: Journal of Engineering Tribology, 2012, Vol. 226, No. 4, pp. 284-305

(Accepted Version)

(39) Greenwood, J.A. and Tripp, J.H. (1970-1971) 'The contact of two nominally flat rough surfaces', Proc. IMechE, 185, pp. 625-634

(40). Teodorescu, M., Taraza, D., Henein, N.A. and Bryzik, W. (2003) 'Simplified elastohydrodynamic friction model of the cam-tappet contact', SAE Paper No. 2003-01-0985

(41) Eyring, H. (1936) 'Viscosity, plasticity and diffusion as examples of reaction rates', $J$. Chem. Phys., 4, 283

(42) Booker, J.F. (1989) 'Basic equations for fluid films with variable properties’, Trans. ASME, J. Trib., Vol. 111, No. 3, July 1989, pp. 475-483

(43) Hoffmann K.A. and Chiang S.T. (1993) Computational fluid dynamics for engineers Volume I, A Publication of Engineering Education System, Wichita, Kansas, USA

(44) Gore, M., Perera, M., Styles, G., King, P.D. and Rahnejat, H. (2011) 'Wear characteristics of advanced honed and cross-hatched coating cylinder liners', STLE Annual Mtg. \& Exhib., Atlanta, Georgia, USA, 1-4

(45) Al-Samieh, M.F. and Rahnejat, H. (2001) 'Ultra-thin lubricating films under transient conditions', J. Phys., D: Appl. Phys., 34, 2610

(46) Chong, W.W.F., Teodorescu, M. and Rahnejat, H. (2011) 'Effect of lubricant molecular rheology on formation and shear of ultra-thin surface films', J. Phys., D: Appl. Phys., 44, 165302

\section{Appendices}

\section{Appendix A:}


Proceedings of the Institution of Mechanical Engineers, Part J: Journal of Engineering Tribology, 2012, Vol. 226, No. 4, pp. 284-305

(Accepted Version)

The following are the terms used in equation (32):

$$
\begin{gathered}
A_{i, j}=\frac{p_{i-1, j}+p_{i+1, j}}{\Delta x^{2}}+\frac{p_{i, j-1}+p_{i, j+1}}{\Delta y^{2}} \\
Q_{i, j}=\left[\frac{1}{\rho}\left(\frac{\partial \rho}{\partial p}\right)-\frac{1}{\eta} \frac{\partial \eta}{\partial p}+3 \frac{1}{h} \frac{\partial \delta}{\partial p}\right]_{i, j} \\
M_{i, j}=\left[\frac{1}{h} \frac{\partial h_{s}}{\partial x}-2 U \frac{\eta}{h^{2}}\left(\frac{\partial \rho}{\partial p}+\frac{1}{h} \frac{\partial \delta}{\partial p}\right)\right]_{i, j} \\
N_{i, j}=\left[\frac{1}{h} \frac{\partial \Delta}{\partial y}-2 V \frac{\eta}{h^{2}}\left(\frac{\partial \rho}{\partial p}+\frac{1}{h} \frac{\partial \delta}{\partial p}\right)\right]_{i, j} \\
R_{i, j}=\left\{\frac{\eta}{h^{2}}\left[\left(U \frac{\partial h_{s}}{\partial x}+V \frac{\partial \Delta}{\partial y}\right)+2\left(\frac{1}{\rho} \frac{\partial \rho}{\partial t}+\frac{1}{h} \frac{\partial h}{\partial t}\right)\right]\right\}_{i, j}
\end{gathered}
$$

\section{Appendix B:}

The net thermal power produced through combustion of fuel in the engine can be calculated as:

$P_{c h}=\dot{m}_{f} Q_{L H V}$

where, $\dot{m}_{f}$ is the mass flow rate of the fuel and $Q_{L H V}$ is the lower heating value of the fuel, being $45 \mathrm{MJ} / \mathrm{kg}$. Therefore, the fuel energy released through combustion per engine cycle can be calculated from B1.

The mass flow rate of fuel for each cycle at different engine speeds is given in Table B1.

Table B1: Mass flow rate for various engine speeds

\begin{tabular}{|l|l|}
\hline Engine speed (rpm) & Fuel mass flow rate (g/s) \\
\hline
\end{tabular}


Proceedings of the Institution of Mechanical Engineers, Part J: Journal of Engineering Tribology, 2012, Vol. 226, No. 4, pp. 284-305

(Accepted Version)

\begin{tabular}{|l|l|}
\hline 1000 & 0.271 \\
\hline 2000 & 0.606 \\
\hline 3000 & 0.958 \\
\hline 4000 & 1.389 \\
\hline 5000 & 2.188 \\
\hline 6000 & 2.899 \\
\hline
\end{tabular}

The energy consumed by the ring as the percentage of this fuel energy can readily be calculated and is shown in Figure 15. 